\title{
The Effects of Innovation Network Policies
}

Compendium of Evidence on the Effectiveness of Innovation Policy Intervention

Paul Cunningham

and

Ronnie Ramlogan

Manchester Institute of Innovation Research Manchester Business School, University of Manchester http://research.mbs.ac.uk/innovation/ 
This report is part of the Compendium of Evidence on the Effectiveness of Innovation Policy Intervention Project led by the Manchester Institute of Innovation Research (MIoIR), University of Manchester. The project is funded by the National Endowment for Science, Technology and the Arts (NESTA) - an independent body with the mission to make the UK more innovative.

The compendium is organised around 20 innovation policy topics categorised primarily according to their policy objectives. Currently, some of these reports are available.

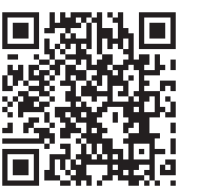

All reports are available at http://www.innovation-policy.org.uk. Also at this location is an online strategic intelligence tool with an extensive list of references that present evidence for the effectiveness of each particular innovation policy objective. Summaries and download links are provided for key references. These can also be reached by clicking in the references in this document. 


\section{Table of Contents}

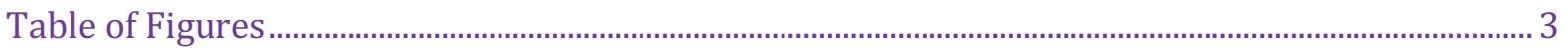

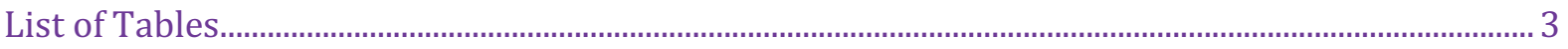

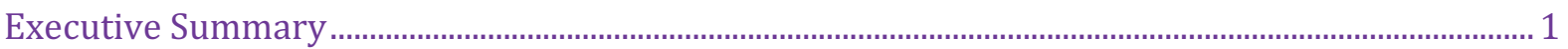

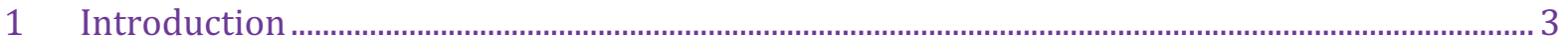

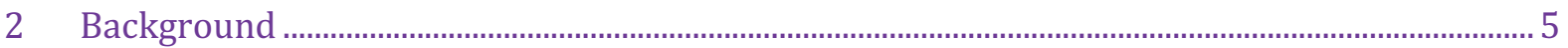

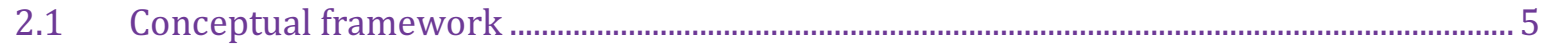

2.1.1 Networks - a working definition.......................................................................................... 5

2.1.2 The rationale for intervention.................................................................................. 6

2.1.3 Overview of typical instruments, target groups, governance issues and practice... 9

$2.2 \quad$ Challenges for evaluating policy ……………............................................................................. 14

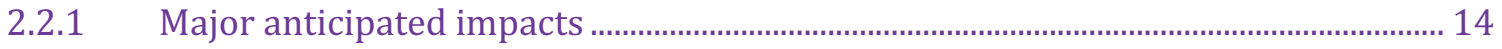

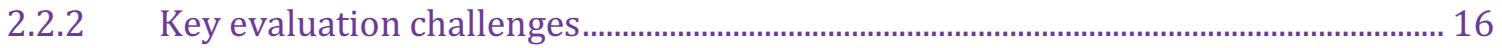

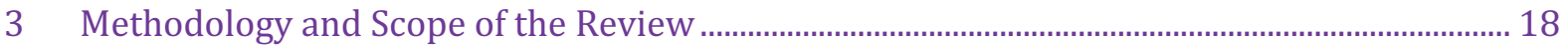

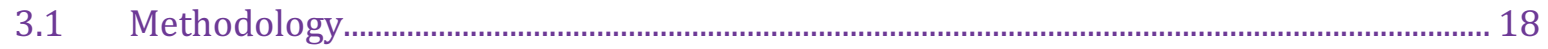

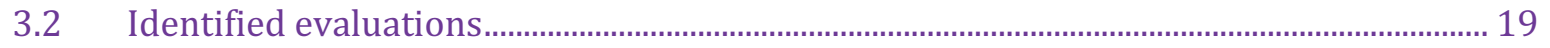

3.2.1 Evaluation reports/studies ………………................................................................. 19

3.2.2 Major broader reviews................................................................................................... 20

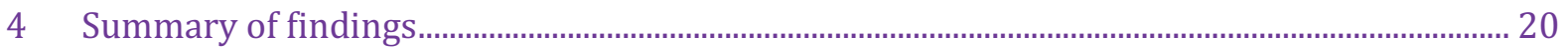

$4.1 \quad$ Evidence from the evaluation literature

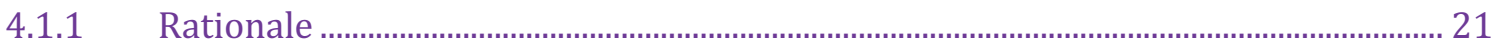

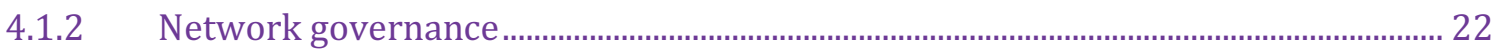

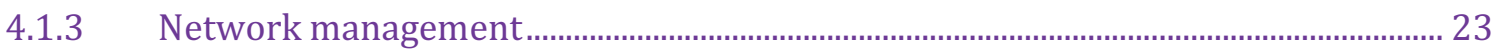

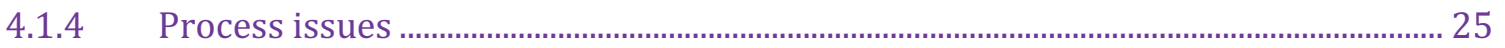

4.1.5 Nature and scope of collaboration and networking......................................................... 27

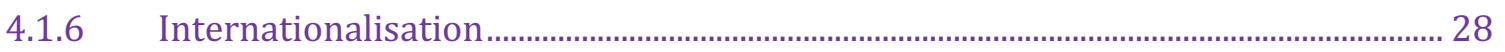

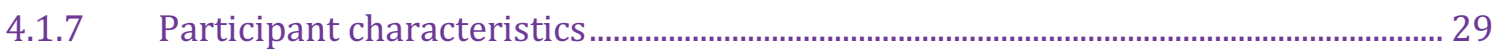

4.1.8 Sustainable Partnerships...................................................................................................... 30

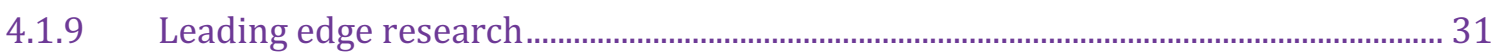

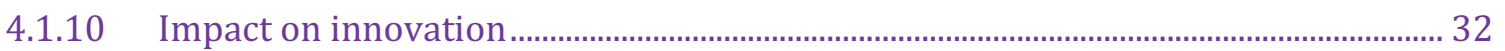

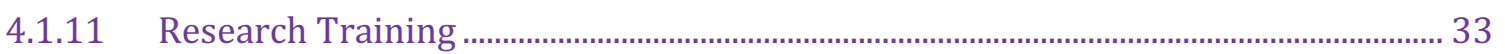

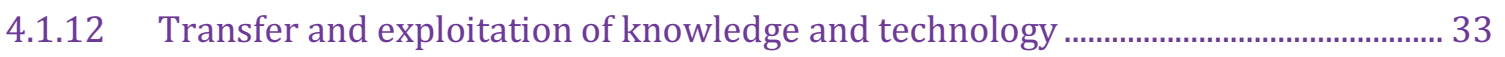

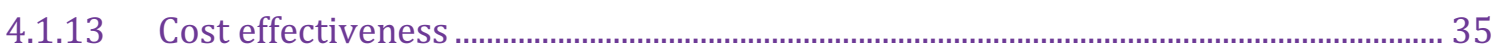

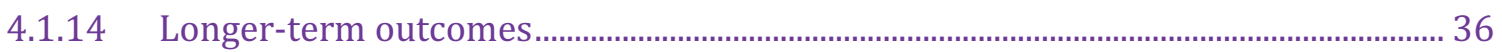




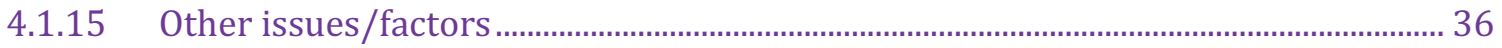

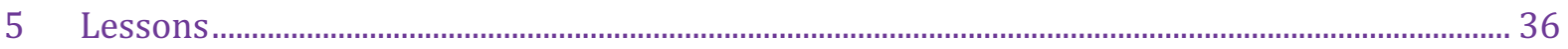

5.1 Lessons concerning networks............................................................................................. 36

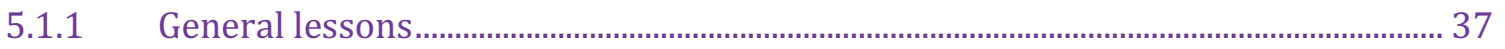

5.1.2 Lessons for policy .................................................................................................................. 37

5.1.3 Firm-to-firm effects .................................................................................................. 38

5.1.4 Lessons from heterogeneous networks ………………………………........................... 39

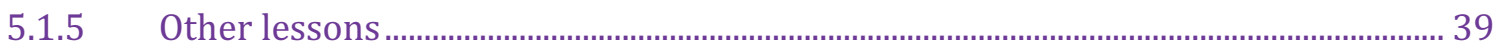

5.2 Lessons for evaluation and the need for future research ........................................................ 39

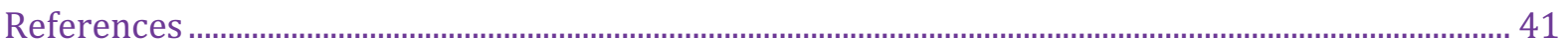

\section{Table of Figures}

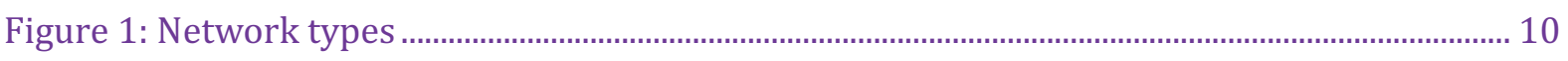

Figure 2: Typology of network support measures ……....................................................................... 10

\section{List of Tables}

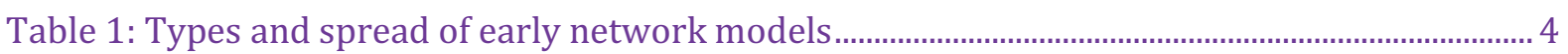

Table 2: Reasons for government intervention to create and support networks ............................... 9

Table 3: Various forms of networks (example of the UK 2004) .............................................................. 11

Table 4: How government may intervene in the support of networks ................................................ 13 


\section{Executive Summary}

Since the late 1970s, networks have become an important component of technology and innovation policy in many countries. Networks allow for rapid learning and facilitate the reconfiguration of relationships between suppliers (in the case of companies) and producers of knowledge (other companies or research institutions); they can also stimulate the development of additional cooperative activities including training, technological development, product design, marketing or facilitate knowledge pooling, skills sharing, the sharing of facilities, equipment or datasets and the co-development of programmes of joint research. However there are few reasons to believe that such beneficial cooperative relationships can emerge automatically and such failures provide a strong rationale for public intervention.

Governments may intervene in order to facilitate the establishment or continued development of a network due to the lack of, or insufficient awareness of, the opportunities they present. Intervention may be used to overcome barriers to network formation such as the fear that there may be unfair appropriation of the benefits accruing from collaborative undertakings. In such circumstances, governments are able to offer knowledge sharing frameworks which provide a level of security as a means of reinforcing the mutual trust upon which successful cooperative arrangements rely. Intervention can also be used to guide firms towards network membership (either with other firms or with the science base) in order to overcome technological "lock-ins", to enter a new area or to change management practices.

This report reviews and reflects on the evidence of the relationship between public support for networks and the impact on innovation. It provides a conceptual background for policy instruments that enhance innovation through the activities of networks, the rationale for their deployment and the main types of approach adopted. Drawing on a review of the available literature, it presents evidence on the impacts of policy interventions on network creation, management and behaviour and - where available - the effects of networks on innovation from a variety of forms of network support. This evidence is analysed against a framework that examines the rationale and goals of network policies and the extent to which expected outcomes have been realised with respect to such issues as collaboration/networking, partnerships, leading edge research, research training and the transfer and exploitation of knowledge and the cost effectiveness and design issues of networks.

Two important issues emerged from the analysis. First, the complexity of networks and the diversity of motivations, rationales, activities, outputs, outcomes and effects make the task of evaluation very difficult. Evaluations tend, therefore, to focus on specific aspects of network behaviour rather than covering the complete set of potential variables. Second, the timing of evaluations is, in many cases, a critical issue. Several of the evaluations and reviews considered found it difficult to make quantitative assessments of network effects, largely because many of the outcomes that could be used as proxies for this measure, such as patenting behaviour, had yet to materialise. Moreover, in many cases there was no baseline of existing capabilities and networking from which progress could be measured. Consequently the evaluation of network quality followed from activity analyses and interview responses.

Among the key lessons that have emerged from the analysis are the following:

i) Networks can have very positive effects on the stimulation of learning processes and the enhancement of skills levels. 
ii) Despite (or because of) the diversity and the complexity of various network forms, there is little evidence (especially quantitative evidence) to explain which forms of network most contribute to innovation or, indeed, whether networks do and, precisely how, lead to innovation.

iii) Strong network management and leadership (such as through a board of directors), coupled with transparent and efficient administrative processes are overwhelmingly cited as essential contributory factors for network success.

iv) Established (informal) networks, or pre-existing connections and relationships form the optimal basis for the establishment of more formal policy-led initiatives for the creation or development of networks.

v) Network participants need to actively manage their networking relationships; experience and network management competencies can strongly influence the gains to be made from network participation.

vi) Policy instruments that facilitate network formation and development (such as support for network brokers or other intermediary organisations) are often successful in achieving these broad objectives. While all firms in a network benefit from being part of a network, the establishment and management costs are borne largely by the network organiser. Public intervention can therefore be used to mitigate this 'free-rider' effect.

vii) Networks fail for a variety of reasons, but lack of demand, trust, commitment and excessive bureaucracy seem to be identified as major causes.

viii) Government intervention can act as both a positive and negative force affecting the sustainability of particular networks and network infrastructures. It can be very difficult to predict the development path of a network since it can be influenced by unpredictable events or by the unintended effects of other policy actions or the regulatory context. In the absence of a bottom-up process of self-determination, top-down initiatives that select target industries, technologies or scientific fields, may not succeed. 


\section{Introduction}

It is widely understood that innovation does not take place along simple linear lines from research, through invention to commercial product or process but is dependent on a variety of feedback loops "within a context of structured relationships, networks, infrastructures and in a wider social and economic context" (Perrin, 2002). Collaboration in research has become a widespread phenomenon, eliciting a number of studies (most recently in the context of 'open innovation'). Extensive use is now made of collaborative agreements as a mechanism for knowledge sharing and exchange (OECD, 2001). Paradoxically, one of the main driving forces behind innovation is competition among firms. Thus, there is inherent tension between sharing knowledge and protecting it and decisions must be made over which knowledge can be traded and of the benefits such exchange may generate.

Nevertheless, as noted by the European Commission (2003), networking now forms a key aspect of company strategy. Rather than single companies, key innovations and related global businesses have become increasingly developed and dominated by market oriented, value-chain based networks. Similarly, individual products and/or services have been superseded by more integrated systems - the nature of innovations is now more systemic. At the same time, the market is seeking packaged solutions in contrast to single technologies or one-off services. Such "packaged solutions (or systemic innovations as they might be called) are developed and produced by networks". Hence, logic dictates that government intervention in support such network activities should represent another element in the innovation policy tool box.

As noted by Freeman (1991), the links by which networks are constructed may range from formal contractual agreements to loosely coupled informal networks. Although formal networks (such as multi-actor research co-operations, joint ventures, etc.) can operate within a (often codified) framework of standardised agreements and commitments between network partners, the 'real business' of knowledge exchange, dialogue and mutual cooperation often operates at the informal level - largely through a process of incorporating tacit knowledge into their learning processes. Lundvall (1992) highlights the fact that the growth of distinct organisational networks comprising a variety of actors at all levels in the economy - what may now be termed innovation ecosystems, has accompanied the rapid growth in complex technologies.

Network membership need not be restricted to firms, indeed the encouragement of the formation of research networks presents a convenient way to address another policy goal adopted by many governments, namely that of increasing the exchange of knowledge between actors in the public and private sectors. Public sector actors typically comprise public sector research establishments ('government laboratories') and institutes of higher education (notably universities). Further significant value may be generated by the facilitation of research networks of public sector actors - to develop critical research mass, or to encourage multidisciplinary approaches to address scientific, technological and societal issues, for example.

The above features explain why networks have become an important component of technology and innovation policy in several countries (and indeed at the supranational level). Briefly, the use of policies to foster inter-firm networks originated in Italy in the 1970s. After the reorganisation of the country into 20 administrative regions, the regional government in Emilia Romagna in north-east Italy introduced a number of initiatives to stimulate collaboration among existing groups of companies. Eligibility for support was conditional on companies 
working in a collaborative network. Within 15 years, these policies had helped raise Emilia Romagna from the seventeenth to the second wealthiest region in Italy and to become the seventh most prosperous region of the EU. The Italian model was then adopted by Denmark, where it was applied through a top down initiative, the Danish Network Programme. Established in 1989, this had the objective of assisting small companies to compete in the Single European Market. A major feature of the programme was the use of brokers to facilitate the development of inter-firm networks. Within eighteen months, around 3,500 Danish companies had become involved in networks. Following the success of the Danish Network Programme, it was adopted in various forms by a number of further countries, including Norway, Australia, the United States, Canada, New Zealand and the United Kingdom. (Martin, et al., 2004) - see Table 1 below.

Table 1: Types and spread of early network models

\begin{tabular}{|l|c|c|c|c|c|}
\hline Country & Broker Used & Cluster Focused & $\begin{array}{c}\text { Part of'one- } \\
\text { stop-shop' SME } \\
\text { assistance }\end{array}$ & $\begin{array}{c}\text { National v } \\
\text { Regional }\end{array}$ & $\begin{array}{c}\text { Resources } \\
\text { relative to } \\
\text { Population }\end{array}$ \\
\hline Denmark & Yes & No & No & National & Large \\
\hline Norway & Yes & No & No & National & Large \\
\hline Australia & Yes & No & Yes & National & Large \\
\hline US & Some places & Some places & No & Regional & Small \\
\hline New Zealand & Yes & No & Yes & National & Large \\
\hline Canada & Yes & Some places & No & Both & Medium \\
\hline UK & Yes & No & Yes & National & Large \\
\hline Spain & Yes & No & Yes & Regional & Large \\
\hline Netherlands & Sometimes & Yes & Yes & National & Medium \\
\hline
\end{tabular}

Source: Liston, 1996.

A study by the OECD (2001) notes that "by stimulating co-operation among the different actors in the innovation system, policy makers expect that the innovation potential can be better exploited in firms, both existing and new, in research, and in society as a whole". The report concludes that questions remain over the issue of appropriate policies is not clear-cut and that there is a need to clarify "the rationale and instruments for facilitating networking with the aim of generating optimal knowledge circulation and sharing in a context of intense competition". This conclusion remains valid and forms the underlying rationale for this report.

This report, one of a series produced under the NESTA Compendium of Evidence on the Effectiveness of Innovation Policy Intervention, will first focus on setting the broad conceptual background for policy instruments that focus on the enhancement of innovation through the activities of networks, the rationale for their deployment and the main types of approach adopted. We also provide a simplistic definition by which we distinguish networks from related innovation policy concepts such as clusters and R\&D collaboration. This is followed by an overview of the available literature, both in the form of evaluation reports and in secondary academic and grey literature which explicitly present or reflect on the variety of forms of network support and on the evidence for its impact on innovation. Next, we will organise the available evidence according to the nature of the impacts that have been documented and the metrics (and their associated methodologies) that have been used to analyse such impacts. Finally, the report will present the main lessons learned, for example in terms of the main types of impact identified, the effect of contextual conditions on policy implementation (including interactions with other forms of innovation support), the implications for evaluation 
methodologies and more generally in terms of improving the understanding of innovation networks

\section{Background}

\subsection{Conceptual framework}

\subsubsection{Networks - a working definition}

As a companion report in this series covers policies designed to support clusters, it is important to define precisely what is meant by networks in the context of this report. According to the European Commission (2003) networking measures comprise one of a set of direct measures which specifically "include support for clubs which exchange information and for activities such as foresight programmes which aim to develop common visions around which future oriented R\&D networks can be formed".

As noted above, innovation occurs within the context of multiple forms of informal and formal collaboration. Recent policy attention has tended to focus on formal mechanisms of cooperation among groups of firms, or among firms and research institutions/centres of technical excellence (OECD, 2011). However, much of the policy literature addresses network and clusters policies in an almost interchangeable manner, with little distinction between them.

Cluster policies gained prominence with the work of Porter (1990) where they were associated with (national) competitive performance. Since then, governments have adopted a range of cluster approaches at the national and regional levels. Some of these be used to identify firm level networks and explain their competitiveness (micro level), typically with a strong emphasis on SMEs in the context of industrial, regional and/or innovation policy (European Commission, 2003). The implication here is that network policies operate at the micro-level between more restricted sets of innovation actors.

The European Commission (2003) report makes a further interesting distinction in that "industry-research clustering is basically about networking around specific knowledge bases or technologies and as such is closer to horizontal networking than vertical networking". Here we stray into the area of science-industry collaboration - another topic reviewed by this series of reports, although we recognise that networks may encompass a range of actors from the public and private sectors (and, indeed, from the third sector).

According to the European Commission (2006), the term 'innovation cluster' refers to "groupings of independent undertakings - innovative start-ups, small, medium and large undertakings as well as research organisations - operating in a particular sector and region and designed to stimulate innovative activity by promoting intensive interactions, sharing of facilities and exchange of knowledge and expertise and by contributing effectively to technology transfer, networking and information dissemination among the undertakings in the cluster". Clearly, this implies a much more intensive and sophisticated level of activity than might be expected within an innovation network.

In their study, Stahl-Rolf and colleagues (2002) define networks as the "usually formal collaboration of partners aiming at increasing the competences and innovativeness of the partners and to generate innovations". 
In order to make this definition operational, they applied a number of criteria:

- Several projects may be conducted within the same network structure.

- While the network may be oriented towards the production of producing innovations, the role of networking policy is not to directly support innovation projects but to support cooperation and the building of competence which will result in innovations.

- For this reason, networking activities such as the exchange of experience, communication channels, etc. are part of the programme.

- Network management is institutionalised (often through some form of coordinating office, etc.).

However, as they further indicate, in many instances, the stimulation of networking activities forms an integral, if not the most important part, of broader and more encompassing cluster programmes. Thus, the characteristics of schemes supporting networks of innovation and those targeting innovation-oriented clusters can often be very similar. Accordingly, many of the conclusions arising from the evaluation of network schemes are equally valid as those for evaluations of cluster programmes.

In order to provide a pragmatic working definition of network policies (and to distinguish them in particular from cluster policies), in this work we refer to networks as measures aimed at promoting or sustaining the linkage of firms and/or knowledge producers where the activities concerned are centred on a specific technological or problem-oriented topic for the primary purpose of knowledge and information sharing. The basis of the network relationship is thus not based on specific individual projects or similar operational modalities such as personnel mobility or placement activities (which fall into area of schemes for R\&D collaboration) but on broader notions of knowledge exchange between larger groups of actors. Whilst networks can be linked to the idea of innovation platforms, for our purposes they are not as developed as these (i.e. they are not necessarily focused on industry sectors).

Critically, from the perspective of this report, networks are not necessarily geographically colocated (which is the primary criterion used to differentiate them from clusters). Support for this argument comes from the literature ${ }^{1}$ which has increasingly emphasised that it is important to connect regional centres of activity to broader national and international networks rather than focusing exclusively on strengthening regional linkages. The inclusion of academic actors in regional and national networks of business actors is seen as important since the former are frequently embedded in international research networks and thus can function as bridges to a broader knowledge base (Bruno, et al., 2011). Nevertheless, it is inevitable that several of the findings of this report echo those reports within this Compendium covering innovation clusters and science-industry cooperation.

\subsubsection{The rationale for intervention}

A theoretical and conceptual rationale for the application of public innovation policies in support of networks can be traced through an extensive literature base. A seminal work in this area is that of Freeman (1982) in which the systems approach to innovation was first introduced. The resulting shift of focus to include the notion of systemic failures (rather than just market failures), highlighted the significance of actors, and the relationships between them, as a target for innovation policy. Initially focused on 'innovation bottlenecks' - and still

\footnotetext{
${ }^{1}$ For example, McDonald, F, Huang, Q, Tsagdis, D, \& Tuselmann, H., 2007.
} 
reflecting a rather linear view of systemic innovation - this led to a growth in the use of measures aimed at the support of collaboration and cooperation in R\&D and innovation, at the expense of measures that directly supported R\&D-related activities (which deal with isolated innovation 'events'). Further sophistication followed, shifting from the support of single projects carried out by, often limited numbers of, academic and industrial actors to wider ranging support for network development.

From the industry perspective, networking has become a key element of company strategy instead of single companies, market-oriented, value-chain based networks now tend to dominate the development of key innovations and related global businesses. This provides government with the opportunity to act as facilitator with policies based on the innovation systems approach (European Commission, 2003). Again, a key target for support is the recognition (or assumption) that systemic failures are often due to sub-optimal knowledge flows arising from insufficient industry-science linkages - although, following the definition adopted above, this does not include single collaborative project or personnel mobility based activities but wider collaborations. In a sense, the rationale for network formation and, hence, for their support is the assumption that the whole (the network) is greater than the sum of its individual parts (the network members) in terms of the activities performed.

Thus, networks can allow for rapid learning and facilitate the reconfiguration of relationships such as with suppliers (in the case of companies) or with producers of knowledge (who may be other companies or research institutions). As noted by the OECD (2011), networks can stimulate the development of additional cooperative activities around a diverse range of issues including training, technological development, product design, marketing, exporting and distribution. Similarly, in the field of scientific research, networks can develop activities based around knowledge pooling, skills sharing, the sharing of facilities, equipment and datasets, student and staff exchanges, the co-development of programmes of joint research, copublication and others. Again, the objective may be the development of a critical mass in one or several activities, but one that is not necessarily geographically co-located and which may even be virtual.

In these contexts, there are reasons that provide justification for government involvement in supporting the development of networks. Governments may intervene in order to facilitate the establishment or continued development of a network due to the lack of, or insufficient awareness of, the opportunities that may be afforded by networks. Government intervention may also overcome barriers to network formation such as the fear that there may be unfair appropriation of the benefits accruing from collaborative undertakings (OECD, 2011). In this case, governments are able to offer knowledge sharing frameworks which provide a level of security as a means of reinforcing the mutual trust upon which successful cooperative arrangements rely. A typical goal for intervention is to guide firms towards network membership (either with other firms or with the science base) in order to overcome technological "lock-ins", to enter a new technological area or to change management practice, etc. (European Commission, 2003).

Where the potential members of a network are geographically dispersed, intervention may be necessary to overcome inertia for their formation due to problems with coordination. In a similar fashion, government support may provide the central coordination and administration required to run the network, which may be beyond the resources or capacity of any single network member. Another opportunity for support is through the provision of channels of 
communication for the exchange of information about the network, such as members' details, information on activities and meetings and the dissemination of research outcomes, etc. Typically, this may be provided through the provision of a dedicated web resource (an illustrative example of which is the extensive web site that supports the UK Knowledge Transfer Networks and which offers both information resources and other services for both the public (open access) and for KTN members (restricted access) ${ }^{2}$.

Notwithstanding the barriers outlined above, networks can occur organically in a bottom-up fashion around issues of common interest to the network members. However, government support may aim to stimulate the general sharing of information between broader sets of network members (who may be drawn from the public, academic or private sectors, or further afield, such as NGOs and charitable foundations). Likewise, such support may focus on more specific goals - often aligned to scientific and technological themes or fields deemed to be of policy significance at regional, national or other levels and where the development of a critical mass of activity is desirable.

A further benefit of support for networking is that, by reducing the barriers or costs of network entry, network members may opt for a variety of levels of engagement. This may range from collaboration in specific research activities, for example, which involve the commitment of resources to participation in general level discussions over specific issues of mutual interest through to participation merely as an observer, incurring a minimal draw on resources. This flexibility makes networks attractive to actors across a range of scales, from SMEs (or even individual entrepreneurs) to large public research establishments or multi-national companies.

Drawing on the literature, Martin et al. (2004), offer the following benefits for the formation of networks:

- Increased scale and scope of activities

- Shared costs and risks

- Improved ability to deal with complexity

- Enhanced learning effects

- Positive welfare effect (increased R\&D efficiency and overall R\&D expenditure)

- Flexibility (in hierarchies)

- Efficiency (of knowledge transfer)

- Speed (of response to opportunities).

Citing O'Doherty (1998), they note that the benefits of networking can be summarised as follows:

- Material benefits: firms can increase sales and lower production costs by working together.

- Psychological benefits: as firms eliminate their isolation they learn that their problems are shared by others.

- Developmental benefits: By promoting interaction with other firms, networking increases learning and the ability to adapt to the changing economic environment.

${ }^{2} \underline{\text { http://www.innovateuk.org/deliveringinnovation/knowledgetransfernetworks.ashx }}$ 
Finally, Martin et al (2004) provide an overview of the major reasons for government intervention in the support of networks (note that the authors use the terms networks and clusters interchangeably) (see Table 2)

Table 2: Reasons for government intervention to create and support networks

\begin{tabular}{|c|c|c|}
\hline Obstacles & $\begin{array}{l}\text { Network/cluster-oriented } \\
\text { assistance strategies }\end{array}$ & $\begin{array}{l}\text { Assistance } \\
\text { instruments }\end{array}$ \\
\hline $\begin{array}{l}\text { Insufficient awareness of the } \\
\text { benefits }\end{array}$ & $\begin{array}{l}\text { - Identify incipient clusters; } \\
\text { - Market cluster idea. }\end{array}$ & $\begin{array}{l}\text { - Sector/SWOT analysis in the } \\
\text { regions; } \\
\text { - Inventory of initial stages of } \\
\text { clusters; } \\
\text { - Identification/communication } \\
\text { of the benefits of networks/ } \\
\text { clusters. }\end{array}$ \\
\hline Little willingness to cooperate & - Promote dialogue. & $\begin{array}{l}\text { Dialogue promotion/exchange } \\
\text { of information (network } \\
\text { programs); } \\
\text { - Promoting the formation of } \\
\text { regional clusters by supporting } \\
\text { joint activities (e.g. procurement } \\
\text { of inputs, export marketing); } \\
\text { - Promoting alliances, e.g. by } \\
\text { linking public tenders to the } \\
\text { formation of a consortium; } \\
\text { - Training and upgrading } \\
\text { of networking specialists } \\
\text { (brokerage, in-/outsourcing } \\
\text { etc.). }\end{array}$ \\
\hline Weak internal cluster structures & $\begin{array}{l}\text { - Promote cooperation; } \\
\text { - Promote investment; } \\
\text { - Improve institutional support. }\end{array}$ & $\begin{array}{l}\text { - Promotion of management } \\
\text { competence and } \\
\text { communication culture among } \\
\text { cluster members; } \\
\text { - Bringing together suitable } \\
\text { (brokerage) partners for } \\
\text { cooperation/investment; } \\
\text { - Promotion of start-ups which fit } \\
\text { the cluster. }\end{array}$ \\
\hline $\begin{array}{l}\text { Underdeveloped innovation } \\
\text { power }\end{array}$ & $\begin{array}{l}\text { - Create favourable framework } \\
\text { conditions; } \\
\text { - Improve R \& D offerings; } \\
\text { - Adapt training and upgrading to } \\
\text { needs. }\end{array}$ & $\begin{array}{l}\text { - Reform of legal and } \\
\text { administrative rules and } \\
\text { regulations; } \\
\text { - Reform of tax/incentive system; } \\
\text { - Restructuring of training, } \\
\text { upgrading and research } \\
\text { services. }\end{array}$ \\
\hline $\begin{array}{l}\text { Obstructive government } \\
\text { regulations }\end{array}$ & $\begin{array}{l}\text { - Create favourable framework } \\
\text { conditions. }\end{array}$ & $\begin{array}{l}\text { - Identification of regulatory } \\
\text { obstacles in cluster-specific } \\
\text { forums; } \\
\text { - Reform of legal and } \\
\text { administrative rules and } \\
\text { regulations; } \\
\text { - Reform of the tax/incentive } \\
\text { system. }\end{array}$ \\
\hline Limited access to information & $\begin{array}{l}\text { - Improve the systems for the } \\
\text { collection, processing and } \\
\text { dissemination of information; } \\
\text { - Training and upgrading in } \\
\text { knowledge management. }\end{array}$ & $\begin{array}{l}\text { - Exchange of information; } \\
\text { - Building up information systems } \\
\text { (such topics as marketing, } \\
\text { technology, research results } \\
\text { etc.); } \\
\text { - Establishing/expanding } \\
\text { cluster-specific technology and } \\
\text { research centres; } \\
\text { - Supporting cooperative } \\
\text { research and development as } \\
\text { well as cooperative technology } \\
\text { transfer. }\end{array}$ \\
\hline
\end{tabular}

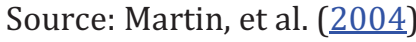

\subsubsection{Overview of typical instruments, target groups, governance issues and practice}

A useful 'evolutionary model' of the increasing complexity through which firm to firm relationships may be transformed into fully fledged innovation networks is provided by the OECD (2004). Around one-fifth of the networks identified across eight European countries were of the 'complete innovation network' type, comprising a range of industry actors, universities and government laboratories (see Figure 1). The figure contains no geographic dimension and thus serves equally well as a typology for networks or clusters (following our working definition). 
Figure 1: Network types

\begin{tabular}{|l|l|l|}
\hline Type of network (Survey of 8 European countries & ) & \% share \\
Weak or no network linkages \\
Equipment supplier (ES) \\
dominated networks
\end{tabular}

1. Belgium, Denmark, France, Germany, Ireland, Italy, Netherlands, Norway. Source: $\underline{\text { OECD, } 2004}$

The same report also provides a broad typology of the types of support for networks, partnerships and clusters, populated with specific examples from a number of OECD countries.

Figure 2: Typology of network support measures

\begin{tabular}{|c|c|c|c|c|c|}
\hline & \multicolumn{2}{|c|}{ Generic } & \multicolumn{3}{|c|}{$\begin{array}{l}\text { Targeted at industry-science relationships } \\
\text { (PP/Ps for research) }\end{array}$} \\
\hline & $\begin{array}{l}\text { Awareness of } \\
\text { networking } \\
\text { opportunities and } \\
\text { search for partners }\end{array}$ & $\begin{array}{l}\text { Active support to } \\
\text { the organisation } \\
\text { and operation of } \\
\text { networks }\end{array}$ & $\begin{array}{l}\text { Financial and } \\
\text { institutional support }\end{array}$ & $\begin{array}{l}\text { Regulatory } \\
\text { approach }\end{array}$ & Tax incentives \\
\hline \multirow{4}{*}{$\begin{array}{l}\text { SME- } \\
\text { specific }\end{array}$} & \multirow{2}{*}{$\begin{array}{l}\text { Innovation Portal } \\
\text { (Canada) } \\
\text { Inno-NET Portal } \\
\text { (Korea) }\end{array}$} & $\begin{array}{c}\text { Co-operative } \\
\text { research (CRAFT) } \\
(E U)\end{array}$ & & & \\
\hline & & \multicolumn{2}{|c|}{ Pro-Inno (Germany) } & & \\
\hline & \multirow{2}{*}{\multicolumn{2}{|c|}{$\begin{array}{l}\text { Innovation Relay Centres } \\
\text { (most European countries -- plus a pan- } \\
\text { European IRC network) } \\
\text { INSME }\end{array}$}} & TEFT (Norway) & & \\
\hline & & & SBIR / STTR & ited States) & \\
\hline \multirow{2}{*}{$\begin{array}{l}\text { Non } \\
\text { SME- } \\
\text { specific }\end{array}$} & $\begin{array}{l}\text { CORDIS Technology } \\
\text { Marketplace (EU) }\end{array}$ & \multicolumn{2}{|c|}{$\begin{array}{l}\text { Centre of Expertise \& Cluster programmes } \\
\text { (Finland) }\end{array}$} & $\begin{array}{l}\text { Target }(15 \%) \text { for } \\
\text { SME involvement } \\
\text { in the } 6^{\text {th }} \mathrm{FP}(E U)\end{array}$ & $\begin{array}{c}\text { Tax deduction on } \\
\text { collaborative R\&D } \\
\text { (Denmark) }\end{array}$ \\
\hline & & & $\begin{array}{l}\text { Innovation Consortia } \\
\text { (Denmark) } \\
\text { CRCs (Australia) } \\
\text { K centres (Austria) }\end{array}$ & & \\
\hline
\end{tabular}

Source: OECD, 2004.

Another useful overview of the various forms that networks may take is provided by Pittaway, et al. (2004) in their review of networking activities in the UK (see Table 3). Their categorisation 
is structured according to the specific characteristics, spatial location and composition of the various network forms.

Table 3: Various forms of networks (example of the UK 2004)

\begin{tabular}{|c|c|}
\hline Form of Network & Explanation \\
\hline Netwark Types & $\begin{array}{l}\text { A few studies have attempted to identify netwark forms or types. More generally } \\
\text { networks and network relationships are characterised by the development of direct } \\
\text { ties, indirect ties, structural holes, intra and inter-organisational relationships. }\end{array}$ \\
\hline Knowledge Networks & $\begin{array}{l}\text { Study on knowledge networks focuses on how networks create and transfer } \\
\text { knowledge. Studies show the importance of local knowledge in the netwarking } \\
\text { capacity of small firms, the importance of regionalism and explain how knowledge } \\
\text { netwarks are constructed. Much of the work examined explores issues associated } \\
\text { with learning through networks and illustrates their importance for sharing tacit } \\
\text { knowledge. }\end{array}$ \\
\hline Investment Networks & $\begin{array}{l}\text { The UK equity gap is generally well documented but the UK 'investment netwark } \\
\text { gap' has been explared less. Studies in this area have focused an the importance of } \\
\text { investment networks and have illustrated their value for early stage investment and } \\
\text { for spreading the risk amongst equity investors. Jaint investment networks have } \\
\text { been shown to be crucial both in venture capital finance and for informal business } \\
\text { angel investment. The sharing of information an investment portfolios has also } \\
\text { facilitated more effective investrnent levels in promising businesses. Likewise } \\
\text { informal investment referral networks between investors have shown their value for } \\
\text { enabling prospective entrepreneurs to meet appropriate investors. }\end{array}$ \\
\hline Netwark Clusters & $\begin{array}{l}\text { Much research has been carried out on the spatial proximity of firms in dusters and } \\
\text { the benefits of dustering for netwarking. Some studies consider this to be the } \\
\text { distinguishing factor between innovative and less innovative regions. How firms } \\
\text { relate to each other in clusters has been less well considered. It has been argued } \\
\text { that the mere proximity of firms does not necessarily impact on networking or } \\
\text { innovation. Some duster studies do illustrate the importance of conglomerations for } \\
\text { attracting venture finance. }\end{array}$ \\
\hline $\begin{array}{l}\text { Regional and National } \\
\text { Netwarks }\end{array}$ & $\begin{array}{l}\text { Sorne of the studies reviewed explore intra-regional, inter-regional and international } \\
\text { netwarks. These studies typically draw on ecanomic geography but also indude } \\
\text { studies of Multinational firms. Many of these identify the importance of region-to- } \\
\text { region knowledge exchange via netwarks and its impact on innovation. In certain } \\
\text { industries these studies illustrate the importance for international netwarking even } \\
\text { for very small firms e.g. biotechnology }\end{array}$ \\
\hline $\begin{array}{l}\text { Science-industry } \\
\text { Networks }\end{array}$ & $\begin{array}{l}\text { Although the study focused primarily an business-to-business networks science- } \\
\text { industry relationships appear to be important for netwark brokerage and frame-- } \\
\text { breaking change. For example, non-business systems were viewed to provide a } \\
\text { different stimulation for innovation, which could not be found within normal business } \\
\text { routines. These interactions were viewed to take place most effectively between } \\
\text { individuals, where communicating networks of scientists and engineers work } \\
\text { together. Science enterprise was also shown to enable the creation of netwarks } \\
\text { around focal points promoting the development of dusters in the same way that } \\
\text { large organizations can. Proximity to publicly funded research organisations was } \\
\text { also shown to be instrumental in the innovative effort of the small firm sector. }\end{array}$ \\
\hline Supply Chain Networks & $\begin{array}{l}\text { There were a large number of studies examining the supply chain network and its } \\
\text { impact on innovation; particularly product innovation. These studies illustrate that } \\
\text { engaging suppliers and austomers in networks enables information exchange } \\
\text { leading to more effective innovation. Whilst these may seern to be in the main to } \\
\text { be naturally accurring, firms that had adopted a strategic approach to the } \\
\text { development and management of relationships with customers and suppliers were } \\
\text { found to be more innovative. }\end{array}$ \\
\hline Strategic Networks & $\begin{array}{l}\text { The strategic network hiterature explores networks as a strategic resource for firms } \\
\text { and seeks to explain how firms can manage them more effectively. Such work } \\
\text { explares how arganizations can exercise strategic cantrol over their relationships and } \\
\text { explains how cancepts of network managernent can be induded in the strategic } \\
\text { planning process. }\end{array}$ \\
\hline
\end{tabular}

Source: Pittaway, et al. (2004)

In a review of four Centres of Excellence (CoE) programmes (in Finland, the Netherlands, Norway and Sweden) Lemola and Lievonen (2008) note that all address the same broad failures in the innovation systems of their respective countries, namely:

- weak co-operation between innovating organisations

- low number of (growth-oriented) start-up companies 
- the threat of multinationals relocating their R\&D activities to low-cost countries.

According to Lemola and Lievonen (2008), all the programmes, which can be categorised as support for network development, share a set of common characteristics:

- they are explicitly driven by the strategic requirements of participating companies;

- they involve intensive collaboration between private enterprises and research groups from public knowledge organisations

- they are based on institutionalised long-term financing and collaboration commitments by private firms and other participants

- they emphasise oriented basic research rather than short-term applied research

- they tend to emerge in sectors of the economy in which technology progresses at a slow rather than revolutionary pace

- they are expected to perform well in acquiring RDI funding also from sources other than the CoE funding programmes

- they are designed to attract top international researchers and world class companies, and

- they take advantage of the principles of open innovation in partner-owners' mutual collaboration, although there may be formal or informal restrictions to collaboration with partner companies' competitors..

A further illustrative example is that of the Knowledge Transfer Networks (KTN) operated by the Technology Strategy Board in the United Kingdom. The objective of a KTN is "to improve the UK's innovation performance, by increasing the breadth and depth of the knowledge transfer of technology into UK-based businesses, and by accelerating the rate at which this occurs. Networks are aligned to, and actively contribute to, the goals of the Technology Strategy Board".

The KTN website sets out the following specific aims of a KTN:

- "To deliver improved industrial performance through innovation and new collaborations by driving the flow of people, knowledge and experience between business and the science-base, between businesses and across sectors;

- To drive knowledge transfer between the supply and demand sides of technologyenabled markets through a high quality, easy to use service;

- To facilitate innovation and knowledge transfer by providing UK businesses with the opportunity to meet and network with individuals and organisations, in the UK and internationally;

- To provide a forum for a coherent business voice to inform government of its technology needs and about issues, such as regulation, which are enhancing or inhibiting innovation in the UK".

Stahl-Rolf and colleagues (2002) provide the definition used by the German Federal Ministry of Education and Research for their "Kompetenznetze" (competence networks). These are characterized by the following criteria:

- They may have a thematic, strategic, and/or regional focus

- They share common guidelines, targets

- They adopt an integrative approach based on:

$\circ$ scientific and technological know-how 
$\circ$ educational offers
$\circ \quad$ an innovation-friendly general framework

- They involve interdisciplinarity and co-operation, including:

○ close communication and interaction within the network

- co-operation with external partners

- They promote international attractiveness, with:

$\circ$ products leading on international markets

$\circ$ international contacts

The role of government in supporting networks can take a number of forms. These can be categorised at three levels as shown in Table 4 below:

Table 4: How government may intervene in the support of networks

\begin{tabular}{|c|c|c|}
\hline Formation/development & Overcoming network barriers & Forms of supporting activities \\
\hline $\begin{array}{l}\text { Facilitate formation/initiation } \\
\text { of network } \\
\text { Encourage expansion of } \\
\text { network } \\
\text { Develop network relations } \\
\text { (formalisation of tacit } \\
\text { arrangements) }\end{array}$ & $\begin{array}{ll}\text { - } & \text { Enhance mutual trust } \\
\text { - } & \text { Assist in partner searches } \\
& \text { (setting of selection criteria) } \\
\text { - } & \text { Promote awareness of network } \\
\text { (develop network branding) } \\
\text { - } & \text { Promote awareness of } \\
\text { networking benefits } \\
\text { - } \quad \text { Financing network activities } \\
\text { - Financing R\&D project costs } \\
\text { (partially or selectively - i.e. } \\
\text { academic partners only) }\end{array}$ & $\begin{array}{l}\text { Introduce knowledge sharing } \\
\text { framework (IPR, etc) } \\
\text { Organisation of governance } \\
\text { processes, appointment of } \\
\text { governing boards, etc. } \\
\text { Administration of network } \\
\text { (centralisation of data, } \\
\text { communications, organisation of } \\
\text { activities) } \\
\text { Coordination of (higher level) } \\
\text { networking activities } \\
\text { Provision of meeting spaces, } \\
\text { fora, (physical and virtual), } \\
\text { workshops, etc. } \\
\text { Provide advisory role } \\
\text { Offer channels for member to } \\
\text { member communication } \\
\text { Participation as a network } \\
\text { partner (e.g. via government } \\
\text { agencies and laboratories) - } \\
\text { other public/private } \\
\text { partnerships } \\
\text { Government acts as customer for } \\
\text { network outputs }\end{array}$ \\
\hline
\end{tabular}

Source: Authors

Likewise, depending on the aims of the intervention and the key actors involved, the targets for support may also vary, focusing on:

- public sector institutions, research centres, research groups, etc.

- private companies, SMEs only, or mixes of varying sized firms

- mixes of public and private sector actors

- any of the above plus additional stakeholders such as government agencies, NGOs, private research organisations, third sector organisations, etc.

Among other factors concerning the operational characteristics of networks and their performance, this variety of actors and forms of support can pose several challenges for their evaluation. 


\subsection{Challenges for evaluating policy}

Before turning towards impacts, we need to briefly introduce the challenges for evaluating policy. This discussion also explains to some extent why evaluations often focus on the structures and behaviours of networks rather than the ultimate innovation effect and why we therefore have little evidence on the actual innovation impact of network support measures.

\subsubsection{Major anticipated impacts}

Clearly, the anticipated impacts of measures that support networks will derive from their basic rationales. According to Bruno et al., (2011), the rationales for the support of networks share many of the same characteristics as the rationales for the support of science-industry linkages. These are based on a series of expected effects and underlying hypotheses:

- "Overcoming the widespread information and behavioural barriers to the cooperation between the public and private sectors, which greatly limit the frequency and intensity of productive interaction between the communities

- Developing stronger channels to facilitate the flow of knowledge and technology from public research organisations to public and private enterprises in a position to deploy that know how and IP in a commercial setting increasing social returns

- Conducting problem-focused research (as opposed to purely disciplinary academic research), in the expectation that this might expand the total academic effort devoted to user-oriented research and thereby accelerate technological breakthroughs in key areas

- Developing regional capacity (a critical mass of research excellence) in emerging areas adjudged to have strategic potential as an innovation platform for resident businesses, with strengthening national or regional competitiveness globally." (Bruno et al., 2011, p38)

They also note that "unlike other innovation policy instruments, clusters and networks have been systematically evaluated and their impact analysed. [For example, a] recent compilation of macro-economic benefits from success stories on cluster initiatives in the European Union by the IRE subgroup (2008) shows two types of benefits from cluster initiatives". For the purposes of this report, the first of these impacts is relevant: the major anticipated impacts related to knowledge spillovers (such as the creation of formal and informal linkages between actors, the evolution of network populations, reorientation of (research and other) activities and increases in related knowledge transfer activities. (The second type of benefit related to the increase in the attractiveness of the hosting regions and falls into the scope of cluster support).

The same analysis of the evaluation of regional innovation support provided through ERDF funding and co-funding (Bruno, et al. 2011) indicated that evaluations of network support measures tended to cover the broad set of evaluation criteria, i.e.:

- Relevance - was the support justified, were the correct activities covered, were the goals of the intervention appropriate, etc.

- Efficiency - did the resources involved justify the outcomes, could the outcomes have been achieved in a more cost-effective way, etc?

- Effectiveness - to what extent did the intervention achieve its stated objectives, were there unanticipated outcomes, etc?

- Sustainability - were the induced effects and impacts sustainable, what further support would be needed to maintain the activities, etc. 
In their review of network programme evaluations, Stahl-Rolf and Hamann (2003) find that evaluation processes tend to contain the following elements:

- Benchmarking/determination of a point of reference: to understand the counter-factual, i.e. what would have happened in the absence of the policy measure? This allows an assessment of the impact (additionality) of the measure. This implies that design $\mathrm{f}$ the evaluation should be undertaken simultaneously within the design of the programme itself.

- Assessment of the outcome of networking activities: Based on Raines (2002), they note that the evaluation approach should address the following issues:

1) Measuring the impact of the support on linkages between actors and the intensity of networking activities. Potential issues to be addressed within this context include:

- Did the programme result in new members joining the network?

- To what extent are members aware of the network?

- Did the frequency and quality of the linkages within the network increase?

2) Measuring the impact of increased networking activities on individual performance (for example, innovativeness, competitiveness).

3) Measuring the impact of increased participant performance on network or regional performance as a whole.

- Measuring the cost-benefit ratio: the use of cost-benefit ratios in the context of supporting networks and R\&D policy in general, tend to be of less importance in Europe, while in the USA and Canada there is a longer tradition in their use. Our observation here is that, given the difficulty in capturing all the outcomes and benefits from networking, which include intangible benefits (such as behavioural additionality) and a range of knowledge spill-overs, and which, moreover, will accumulate over time, the quantification of such benefits would be highly problematic.

Polt (Chapter 14 in OECD, 2001) identifies the following issues that network interventions seek to address and, hence, can form the basis for the formulation of evaluative questions with which to assess the impact of the programme. These are attractive, in that they may apply to a range of types of network participants:

1. (Increasing) awareness of a networking possibility.

2. (Assisting in the) search for partners.

3. Building trust and a shared knowledge base.

4. $\quad$ Organising the network.

5. Ensuring complementary resources.

6. (Stimulating and ensuring) active co-operation.

In their evaluation of the impact of the Finnish Programmes for Centres of Excellence (CoE) in Research (a network support measure), Hjelt et al. (2009) define an extensive set of impacts which provide a useful illustrative list: The overall objective of the Finnish CoE Programmes was "to enable the emergence of creative and efficient research and researcher training environments of a high international standard that can generate top international research". Two major categories of impact are defined: 
- Societal impacts (on the research of the units themselves, on cooperation and more broadly on society at large), mainly from the perspective of CoEs, partners and endusers of the knowledge generated.

- Impacts on the research and innovation system and on national science and innovation policy, mainly from the perspective of CoEs, host organisations and the planners and implementers of science and innovation policy.

Stahl-Rolf and colleagues (2002) found that the specific outputs from the network will be highly dependent upon their orientation - for example, whether it is research-oriented or marketoriented. In their survey, they identified a broad range of potential indicators, including:

- research intensity and quality (measured by publications and collaborations);

- data on student training and job placement afterwards,

- outcome of research and transfer to industry (measured through patents, licenses, spinoff companies)

- number of innovations

- patents

- mobilisation of venture capital

- return on investment

Clearly, the ease of measuring or deriving metrics and indicators for these impacts will vary enormously and difficulties will be further compounded by the variable time horizons involved for them to come to fruition. These challenges will be explored further below.

\subsubsection{Key evaluation challenges}

The evaluation of innovation network support measures poses a number of challenges which are shared by many evaluations in general. Briefly, these can be linked to issues of: timing; range of activities; scope of impact; information collection; data analysis; counterfactual issues; attribution and others.

Timing and periodicity of evaluations: Network activities can take some time to develop; consequently, their anticipated impacts are not likely to manifest themselves until several years after the creation of the network when the outputs of the various forms of collaborative activity promoted have been realised. Thus, the timing of the evaluation will have to strike a balance between being early enough to deliver timely management information and yet allow sufficient time to pass for sufficient results to be generated. In their review of evaluated network schemes, Stahl-Rolf and Hamann (2003) find that many evaluations are used to provide feedback to management on the operational characteristics of the programmes, focusing on the issue of whether 'the right things have been done' and less on whether 'things have been done rightly (sic) [well]'. The use of evaluation as a management tool implies that evaluation results should be timely and not be available only towards the end of a project.

Moreover, the dynamic nature of networks implies a continuing and constantly evolving development, with new activities being started and new partnerships being formed. Therefore, a range of different impacts will emerge over different timescales as new members join or new activities are initiated. Again, this will pose difficulties for the timing of the evaluation and it may be necessary to undertake two or more evaluations at successive stages of the lifetime of the measure. 
Allied to the previous consideration, the developing maturity of the network implies a need for the policy intervention to adapt and change in order to address different requirements. Therefore, successive evaluations will need to address the changing rationales and modalities of intervention.

Breadth of activities: As has been shown in Section 2.2.1, the range of potential activities that can occur under the auspices of a network implies that a precise specification of anticipated impacts can be highly problematic. Not only is it difficult to derive appropriate metrics for several of these anticipated outcomes, the methodologies required to capture them will also need to be correspondingly diverse (see below).

Scope of impact: Networks, as we have seen, typically encompass an extensive and diverse set of members. Consequently, the impacts on specific members and actors will be equally if not more diverse. In addition, capturing the specific impacts on individual members can be difficult and implies the need for comprehensive sampling approaches that are sensitive to individual outcomes.

While it may be possible to capture this diversity of impacts, it will be equally difficult to translate these to a more aggregate level in order to identify the major effects of a policy intervention.

Similarly, the variable level of participation by the range of actors present in the network (and their possible successive entry over a period of time) also implies a diversity of anticipated impacts.

Collection of information: Again, associated with the above issues, unless the policy measure specifies relatively rigid membership criteria and responsibilities, the loosely structured form of a network and the flexibility of the various forms of member engagement create problems with the systematic collection of evaluation data.

Data collection methods: Associated with the issue of scope, there will be a need to employ a range of data collection approaches in order to capture the types of impact (or more precisely, their derived metrics or proxy metrics). For example, the use of interviews and similar approaches to capture experiential information poses problems for data analysis particularly at an aggregate level, while the use of broad participant surveys may fail to capture important qualitative aspects and unanticipated outcomes. Whilst a broad range of data collection and evaluative approaches may be required, this has clear cost implications.

Counterfactuality, comparison groups and benchmarking: The primary purpose of an evaluation is to determine the effects that the policy intervention has had on the status quo (i.e. what would have happened in the absence of the intervention). However, in the case of network establishment, it is difficult to identify counterfactual examples since it is desirable that the key potential actors of a network have actually become participants (rather than being members of a parallel network with similar goals and activities). Examples of similar networks in different countries or regions may provide a comparison although the issue of context is particularly important given the wide range of participants and underlying framework conditions that may prevail. Similarly, unless a very comprehensive and detailed ex ante assessment of the conditions prevailing before the launch of the network measure has been undertaken, very little baseline data will be available against which the performance of the network may be benchmarked. 
Stahl-Rolf and Hamann found that many of the successful evaluation approaches they encountered in their 2003 review depended on the determination of a reference point or benchmark against which the performance of the network might be assessed. Typically this was undertaken during the selection of the network or network members for funding - information being gathered during this process on the status quo and aims of the potential participants. This information provided a reference point against which subsequent activities could be monitored and the extent to which aims were achieved. As an example, they cite the evaluation of the Austrian Centres of Competence programme where the evaluation made a comparison of performance against the situation at the start of funding. In contrast, in the Finnish evaluations of regional networking in electronics and telecommunication programmes, comparisons were made against international comparators in the same field. Few of the evaluations examined by Stahl-Rolf and Hamann made use of comparison group approaches where participant performance was assessed relative to that of networks that did not receive funding or networks that were funded under different programmes, either in the same country or abroad.

The issue of attribution: A major problem commonly encountered in the evaluation of policy measures is that of ascertaining whether the observed performance of the participants can actually be attributed to the measure itself, or whether they have occurred due to other factors external to the measure. In the case of some of the anticipated impacts of a network, this problem is less acute. For example, the creation of a formal network structure (in which members 'sign up' to participate and where their participation is thus formally logged) would not be achieved without any policy intervention - although informal alliances and partnerships may have developed in the absence of the measure. On the other hand, whether such informal alliances and partnerships would have resulted in the same activities and outcomes cannot be determined in the absence of a counterfactual or benchmark analysis (see above).

Stahl-Rolf and Hamann ( $\underline{2003}$ ) encountered a diverse range of data collection approaches, including: evaluation of the documents provided by the network (document review); interviews with network actors (participant interviews); questionnaire-based written interviews with beneficiaries of networks (structured interviews); analysis of programme portfolio; and peerreview. One particularly encountered challenge concerns the collection of information on "soft factors" - which may be interpreted as qualitative information. They note that current approaches tend to examine the quality of linkages or the awareness for network activities within the framework of participants' surveys (e.g. interviews) and that the evaluation of soft indicators was improving. Without specifying, it is implied that they are referring to the upsurge in the use of actor-network analysis techniques.

\section{Methodology and Scope of the Review}

\subsection{Methodology}

In order to generate a literature base for this report a mix of systematic and non-systematic searches were performed. A first step was to search the existing INNO-Appraisal Repository ${ }^{3}$ for examples of innovation network support programmes. A similar procedure was performed

\footnotetext{
${ }^{3}$ http://www.proinno-europe.eu/repository/inno-appraisal-repository
} 
on the database of policy support measures derived from a study conducted for DG Regio into the evaluation of regional innovation support measures ${ }^{4}$.

A second set of searches was performed on the innovation support measures contained in the combined ERAWATCH-TrendChart database ${ }^{5}$. The measures described in this database contain information on whether or not they have been the subject of an evaluation, sometimes accompanied by a source location for any relevant evaluation reports. Since the information in this database is not always fully up to date, additional Google ${ }^{\circledR}$ searches were performed using the title of the measure. In some instances, this procedure revealed more recent evaluation material, including literature associated with the evaluation of the measure and not restricted to the actual evaluation reports themselves. A similar process was also applied to the titles of the measures identified in the INNO-Appraisal and DG Regio studies, in order to ensure more recent

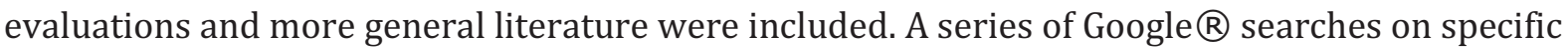
keywords, such as 'innovation networks' and similar terms was also performed.

The general academic and grey background literature dealing with innovation policy evaluation and innovation policy interventions was also scanned for examples of relevant evaluations. Finally, members of the study team were also familiar with particular examples of evaluations.

\subsection{Identified evaluations}

A number of potential evaluation reports and associated literature was identified from the above processes. These were screened in order to exclude examples that specifically concerned cluster policies or cooperation policies (using the definition outlined in Section 2.1.1). However, where the evaluation literature dealt with the issue of networking (although the main policy rationale concerned clusters or cooperation), relevant material was extracted.

The set of evaluations identified for analysis is shown below.

\subsubsection{Evaluation reports/studies}

- Danish Networks programme (1997)

- Evaluation of the Canadian Networks of Centres of Excellence Program (2002)

- The German INNO-REGIO - Programme: empirical results of the complementary research (2002).

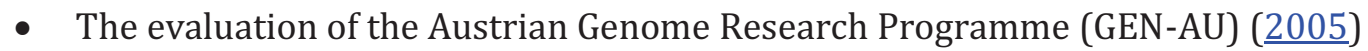

- Evaluation of the Dutch Leading Technological Institutes, (2005)

- Interim evaluation of the Austrian NANO Initiative (2006).

- Evaluation of the Canadian Networks of Centres of Excellence Program (2007)

- Summative Evaluation of the Canadian Networks of Centres of Excellence - New

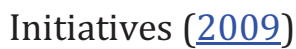

- Evaluation of the Canadian Networks of Centres of Excellence - Centres of Excellence for Commercialization and Research (2009).

- Research Council of Norway/IWT (Belgium), Monitoring and Evaluation of Competence Research Centres (CRC), COMPERA ERA-NET (2010).

- Evaluation of the Innovation Network Denmark (2011).

\footnotetext{
${ }^{4}$ http://ec.europa.eu/regional_policy/information/evaluations/index en.cfm

5 http://erawatch.jrc.ec.europa.eu/erawatch/opencms/research and innovation/
} 
- Case study of the Austrian network programmes - Kplus, $\mathrm{K}_{\text {ind }} / \mathrm{K}_{\text {net }}$ and 'export clusters' (2001)

- Ex-post evaluation of the Belgian IAP programme (phase VI, 2007-2011) (2011).

- Kaashoek, B., Holland, C., te Velde, R and Veldkamp. J, The Flemish Innovation Network: Structure, Workings and Future set-up, IWT (2011).

\subsubsection{Major broader reviews}

- Gelsing, L. and Nielsen, K. (1997) “Promoting Inter-Firm Networks in Industrial Policy — Danish evidence," Modena, Italy, September.

- Martin, T. and Associates, Vision Consulting and Nauwelaers, (2004) C. Innovation Networks, Forfas.

- Nishimura, J and Okamuro, H. (2011) Subsidy and networking: The effect of direct and indirect support programmes of cluster policy, Research Policy, (40) 714-727.

- Pittaway, L., Robertson, M., Munir, K., Denyer, D. and Neely, A. (2004), Networking and Innovation in the UK: A Systematic Review of the Literature, Advanced Institute of Management Research, February.

- Stahl-Rolf, S. and Hamann, 0., (2003) International Experiences with Ex-ante and Ex-post Evaluations of Networks of Innovation, VDI-Technology Centre, Düsseldorf.

- Stahl-Rolf, S. and colleagues (2002). Report on the first Workshop "Networks of Innovation in International Perspective", Düsseldorf 2002.

\section{Summary of findings}

\subsection{Evidence from the evaluation literature}

In order to structure our analysis, we propose the following framework based on the most commonly encountered evaluation objectives (it should be noted that in the analysis of evidence, we have focused on the effects anticipated as a result of networking activities, rather than those from the process of collaboration, either between firms or between industry and academia. These issues are reviewed in another report in this series). This framework starts with preconditions for creating and supporting innovation networks that deliver on their goals, and subsequently turns to the actual impact of the networks on innovation. We have chosen this framework as the majority of evaluations actually focus on preconditions in the creation and support of networks rather than the innovation effects themselves:

- Rationale: What is the niche of the programme? What specific needs are addressed?

- Goals or targets

$\begin{array}{ll}\text { - } & \text { Process issues } \\ \text { - } & \text { Outcomes } \\ \text { - Systemic issues } \\ \text { - Network analysis }\end{array}$

- Outcomes/Impacts: To what extent have the expected outcomes been realized? Specifically, with respect to:

○ Collaboration/networking

- Partnerships

- Leading-edge research

- Research training

- Transfer/exploitation of knowledge and technology 
- Program cost-effectiveness and design issues:

- Could similar outcomes/program impacts be achieved more cost- effectively with some other delivery mechanism?

- How effective is the structure of individual networks in meeting research and knowledge translation objectives?

\subsubsection{Rationale}

Strictly speaking, the rationale for the design and implementation of an innovation policy will have been determined ex ante, prior to its inception. Innovation support programmes are rarely, nor should they be, designed and implemented in the absence of a clearly defined need. However, it may be that the innovation system or the environment in which it operates has changed or that there is a need to assess whether the programme has achieved its objectives or whether its impacts are such that there is no longer a need for it.

A rather self-evident point, but one that is often overlooked in policy design, is identified by Martin, et al., (2004). In their review of Irish networks, they found that "an important condition for the development of a network is that the members perceive that there is a clear need to belong i.e. the network can achieve something that the individual members cannot achieve on their own". An important corollary of this is that the programme (and hence the network) should have objectives that primarily reflect the needs of the participants.

Pittaway et al. (2004) state that, although evidence is limited, the indications are that government policy can indeed create formal arrangements for collaboration (what they term 'implantation'), but those formal collaborations should be led by the existence of established networks. They cite Rychen and Zimmermann (2002) whose study of the microelectronics cluster in the Marseilles area of France showed that, when designing a national policy for the implantation of local clusters or networks in the area, the failure to take local conditions into consideration led to an unsuccessful initiative. The conclusion was that "localised (regional) policy is more appropriate for the formation of infrastructures that tend to depend somewhat on existing networks in a locality". The lesson drawn by Pittaway, et al. (2004) is that policies to create new networks must be sensitive to local/regional demand and receptivity. However, the lesson appears to apply equally to the establishment of more geographically spread (national and international) scales of network.

Further evidence to support this can be found in the evaluation of the Danish Networks Programme. Around three quarters of the total programme budget was spent on networks that were no longer operating by the time of the official evaluation. Similar results were found in the case of the Danish Export Network Programme. Although some positive outcomes were found, such as on the innovation culture of SMEs, many of whom benefited considerably from the valuable experience they gained from the collaboration, the programme "was in some ways misconceived. Although the model was based on the Italian textile districts, a mis-interpretation of the dynamics obtaining in these locales led to a very different final set-up in the Danish programme. It was not appreciated just how difficult it is to create networks (and sometimes this can be because the networking is already present)" (Martin, et al., 2004). The principal policy lesson was that "It is difficult to create 'strategic networks', but the firms involved have shown, we believe, that they can act strategically in a network arrangement." (Gelsing and Nielsen, 1997). 
In contrast to the Danish example, the 2007 evaluation of the Canadian NCE programme found that it was meeting its objectives. These were to increase networking and collaboration among Canadian researchers to develop leading-edge research by creating nation-wide, multidisciplinary and multisectoral research partnerships between universities and the private and public sectors, non-governmental organizations, and others. The evaluation recognised that the programme brought together three unique characteristics at a level not shared by other programmes: "the multi-disciplinary nature of networks; the strong emphasis placed on the training of highly qualified personnel in a multi-disciplinary, multi-sectoral, networked environment; and the objective of solving real-world problems via research and knowledge transfer". It also represented a long-term funding commitment that operated at a national level with emphasis on multi-disciplinarity covering the mandates of all the granting councils. It was highly regarded by stakeholders in terms of S\&T commercialization and translation support and was found to perform better than comparable network programmes in some key areas, including "the creation of structured networks, the establishment of inter-sectoral partnerships, and knowledge utilization, in particular, the commercialization of research findings". (Malatest and Circum Network Inc, 2007).

\subsubsection{Network governance}

The governance of networks plays an important role in determining whether they are successful or not. Based on their review of the UK experience with networks, Pittaway et al. (2004) offer a number of guiding principles or considerations that may be used during the formulation of policies to support network formation and development:

- "Personal and informal networks play a critical role in the effectiveness of networking between firms.

- The degree of diversity of a firm's relationships can have a positive impact on innovation.

- Integrating suppliers, co-suppliers and distributors in innovation projects has a positive impact on firm productivity and the chance of successful innovation.

- Business customers play an important role in innovation efforts by helping firms identify opportunities for innovation.

- Third parties, science partners and institutional mechanisms play an important role in creating a network infrastructure. They can act as neutral network brokers and enable actors to step outside their current 'frame of reference'.

- Effective venture finance networks enable better opportunities for commercial success when firms innovate.

- Firms can manage their networks and what they gain from such relationships depends on their experience and network management competencies.

- There are many different forms of network configuration. These differ depending on the form of innovation and industry and the purpose of the network. Some networks can prevent innovation and can be anti-competitive.

- Networks fail for a variety of reasons - government intervention can act as both a positive and negative force affecting the sustainability of particular networks and network infrastructures."

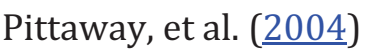

Likewise, in their review of Japanese cluster and network policies, Nishimura and Okamuro (2011) point to some more specific conclusions with regard to the form of support that is most effective in creating innovation networks. In their analysis they considered the relationship 
between different types of support policies in promoting network formation under Japan's Industrial Cluster Project using econometric methods. Support programmes included those related to network formation, for example industry academia collaboration exchange, meetings, symposia seminars, R\&D support and marketing support. They found that the indirect network/coordination was positively related to the creation of industry university government networks. Participation in research meetings, business matching and management consultations were important factors that led to firms participating in networks. By contrast, R\&D subsidies do not seem on their own account to be an important factor in driving network formation. Moreover, indirect support proved to have a greater influence on commercial success and innovation activity.

At the specific level of the participants, governance issues are also significant. In their evaluation of the Dutch Leading Technology Institutes (LTIs), van der Veen et al. (2005) found that in the LTIs active in the food and polymers areas, where (the R\&D intensive part of) industry is rather uniform, joint programming exercises within the LTIs forced the relevant industry partners to discuss their R\&D strategies with each other and with the 'Knowledge Infrastructure' (i.e. the science base). Other sectors, such as metals research and telematics were more diverse and, consequently, joint programming was less strategically oriented and network formation more difficult. In these areas, the relevant LTIs organised the development of roadmaps for certain areas, which was found to have a strong network effect. The finding concerning the association between the uniformity of the industry sector (in terms of its R\&D focus) and the ease of joint programming echoes with observations on the homogeneity of the industry partners by Eickelpasch et al (2002, see section 4.2.6).

One issue to arise in the establishment of networks is whether to create them as legal entities (which could promote long-term commitment and mutual adaptation between the cooperating partners). Although the early Italian evolutionary network structure had adopted this approach, the creation of a legal structure was seen, by the majority of participants in the Danish Network Programme, as "an unnecessary time-consuming activity that did not have any benefit in terms of committing the parties. On the contrary it was argued that the firms involved felt uneasy about this "unnatural" setting. The result was that only peripheral activities were transferred to this new business unit" (Martin, et al., 2004, citing Gelsing and Nielsen, 1997).

\subsubsection{Network management}

Strong leadership is a key factor underlying network performance. It enables a clear focus on important and manageable objectives which were necessary to deliver good results in terms of collaboration, partnership, research and training demands. This was found to be the case in the $\underline{2007}$ evaluation of Canada's NCE programme and a similar conclusion was found in the $\underline{2009}$ evaluation of the Canadian Centre of Excellence for Commercialization and Research. Strong leadership from the Board of Directors, committee members and staff helped in building visibility and support for the organisation of the networks and also in leveraging their expertise and recognition to forge strategic partnerships. A contributory factor was the composition of the Boards and committees which comprised multi-sectoral representation, including members with business investment/venture capital knowledge and experience. This seemed to have a particularly positive effect on the expertise for commercialization and outreach to various sectors (EKOS Research Associates, 2009). 
The role of management was also highlighted in the 2009 evaluation of the NCE-New Initiatives Programme (Bertrand, et. al. 2009) and the INNO-Regio Programme (Eickelpasch, et al., 2002) "for a network to function successfully, it is crucial that it have sound management, and effective organizational structures for information exchange and decision-making". Moreover, Martin et al. (2004) note from their review of Irish network initiatives that "networks that have a leader who is able to articulate clear and concise goals are more likely to be successful then those networks whose members are unclear as to its future direction. The leader should not only be able to communicate the network's long term goals but must also be able to translate those goals into a realistic programme of action".

Strong leadership is equally important in academic networks: the evaluation of the Belgian IAP Programme noted that the evaluation panels were "impressed by the quality of the networking and coordination activities of some of the networks and recommended that good practices should be transferred to the others. Several networks were well managed and well led. Innovative approaches were recognised, for example, the appointment of two academics as "catalysts" -i.e. senior researchers whose specific responsibility is to stimulate interaction within the network. Some networks have developed ideas on how to take the network forward to the next stage. However, in a few cases, the leadership and/or coordination/management were weak and the panels recommended that more attention should be paid to the leadership competencies during selection procedure.

Similarly, Martin et al (2004) point out that the presence of "a major player with the vision and resources can be influential in driving the network forward". Their review found that "the photonics industry network in Canada has been driven by major companies such as Nortel while Pilkington Glass has played a similar role in the photonics network in North Wales" and they cite the example of a French network that failed both because the lack of a key player and critical mass.

Interestingly, the interim evaluation of the Austrian NANO Initiative found that too broad an involvement at all policy levels and funders (the programme is multi-institutionally funded), resulted in a lack of leadership in the programme, and a lack of true ownership. A major challenge of this network programme was thus how to ensure its coordination with other policy instruments: networks, by their very nature, can overlap significantly with other policy support instruments (Technopolis and NMTC, 2006).

Van der Veen et al. (2005) identified formal governance structures (on institute, programme and project level) as important fora for networking in the Dutch LTI Programme, where the mechanisms for the organisation of networking were embedded in the LTI structure. They found that, although there were some general networking activities ('network events'), the most effective activities were the Institute boards and councils and the project exchange mechanisms. The role of brokers, who mediated the initial establishment of the network partnerships, was found to be a key element of the Danish Networks Programme, although they lacked the competence necessary to sustain the networks once they had been created (Gelsing and Nielsen, 1997). However, the evaluation also found that the survival of networks that had been initiated by firms was higher than that of those that were initiated by brokers: three years after the end of the programme, only 33\% of networks established with broker assistance were still in existence compared with $71 \%$ of networks established without broker assistance. 
In Canada's National Centres of Excellence networks, an associated positive factor was the creation of an effective core administrative structure (i.e., management team and administrative and financial management processes) at an early stage of operations. Important requisites for the smooth and effective operation included strong governance practices and principles, financial controls and a human resources strategy, followed by supporting procedures (e.g., "reporting to the Board, standardisation of Board meetings, identifying economies of scale with CECRs linked to a common host"). A further critical factor for some centres was the establishment of a commercialisation advisory committee to review and recommend those commercialisation projects to be taken forward. (EKOS Research Associates, 2009). Critical success factors in the NCE-New Initiatives Programme included "shared visions and interests, including maintenance and clear articulation of [the] network's vision and the related strategic objectives, which increases partners' involvement". One lesson from the programme was the benefit arising from focusing the network around themes or pillars, led by multidisciplinary teams or working groups (Bertrand, et al., 2009).

Many of these success factors could be enhanced if the network management team and/or infrastructure were in place prior to the provision of network programme funding or if there was ready access to a host or partner organisation with a related track record and expertise. The pre-existence of a strong core team or if some of the administrative elements were already in place could help centres move rapidly up the learning curve from start up to full implementation (Canadian NCE-CECR Programme Evaluation, 2009).

\subsubsection{Process issues}

Several studies have found that support measures have considerable impact in terms of establishing networking processes. The 2002 NCE Programme evaluation found that it had been successful in transforming "the way research is conducted". According to the survey results, most respondents believed that "the processes used by the networks were either the same, better, or much better than those arising from "normal" granting agency support". Very few believed they were worse. The range of activities impacted included research, collaboration, multi-disciplinarity, cross-disciplinarity, student training, partnerships with users, knowledge and technology transfer, intellectual property (IP) protection, and development of local and national critical mass. The evaluators did, however, caution that the positive feedback may have been correlated by the level of commitment to NCE goals among some individual researchers or individual networks.

Engendering commitment to the network from its member organisations is an important goal which can contribute to the success of the network. Martin et al (2004) cite the case of the Irish Photonics Association, the establishment of which was supported by Enterprise Ireland. Here, the member organisations recognised that, in order for the network to succeed, it was necessary for them to take ownership of the development process and drive the network forward. Such a sense of ownership led to greater commitment since they saw that its agenda was common to their own.

The external support for the network is also a success factor: In the Canadian NCE-CECR Programme, there was evidence to suggest that benefits could be gained from efforts in the area of communications and outreach in order to "generate awareness of and support among various constituencies such as industry, government, academia and the broader community. Examples of initiatives include Town Hall meetings, Web sites, presentations at various forums and 
conferences, and formal and informal networking" (Canadian NCE-CECR Programme Evaluation, 2009).

Websites and newsletters were identified as important tools for fostering the cohesiveness of network activities. According to survey respondents, these elements were the most frequently used and highly valued forms of communication in the Flemish Innovation Network. The website was also useful for locating potential partners but only as a means of first contact: existing contacts were more often approached directly by mail and telephone (Kaashoek, et al., 2011).

A key objective of the Danish Networks Programme was to enhance the learning processes of SMEs (which was supposed to be facilitated by the approach adopted by the programme), and thereby increase mutual trust, leading to specific co-operative activities. However, the firms' main focus was on short term gains, specifically to expand turnover; learning processes were not considered important. Still, the programme was successful in changing the firms' attitudes towards collaboration: "66\% of firms claimed that the network experience had positively affected their desire to enter new network projects; $50 \%$ co-operated with more firms that they did 5 years previously; $40 \%$ claimed that the network experience had a positive effect on their position in new markets, the ability to undergo changes, management and co-operation with both Danish and foreign firms". (Martin, et al, 2004, citing Gelsing and Nielsen, 1997).

Similarly, a study monitoring the performance of the Austrian WKÖ export 'clusters' programme found, from a survey of the participants, that the clusters were "very much geared towards "information exchange" (27.5\% responses) and "project acquisition" (23.8\% responses). Only for a small minority of firms were joint R\&D (7.2\%), product development (8.4\%)or joint training (4.8\%)seen as motives for participation This is not surprising given the orientation of the programme and the short period of time that had elapsed since the foundation of most of the clusters. Nevertheless, it would be expected that these dimensions of co-operation will be enforced in those clusters that emerge as stable configurations. "Co-operation with other enterprises" improved for $63 \%$ of participants - despite some manifest problems in some clusters" (Polt, in OECD, 2001).

The evidence from the INNO-Regio study (Eickelpasch, et al., 2002) indicated that implementation of $R \& D$ projects undertaken within the network tended to work better in networks of manufacturing firms, especially if the great majority of the participants were high performing companies with innovation capacity and had previously collaborated. In other cases, some problems were encountered with networks being unable to finance their own contributions and provide financial guarantees. Networks with a high share of service firms made slower progress with project implementation: the authors felt that this may have been due to the difficulty in proving the viability of such projects at the outset.

Evidence for Irish experiences with network initiatives tends to highlight the importance of achieving early successes. Such positive feedback at an early stage of the initiative can be crucial in getting participants to continue their involvement in the network. Martin et al. (2004) state that "it is vital that networks structure their objectives and work programme to ensure that members can see a return for their investment in the short term". 


\subsubsection{Nature and scope of collaboration and networking}

One of the key impacts of network programmes is to facilitate a wider range of possible collaborations than would have been the case without the network resources. The Canadian NCE evaluation report conducted in the 2007 concluded that collaboration "can be fostered by various mechanisms: competitions emphasizing cross-team efforts, of course, but also insistence on the multi-disciplinarity of research projects, the composition of network structures (such as the research management committee), and an integrated vision of the problem at hand". The NCE Programme was found to have increased the likelihood of collaboration as well as the size of collaborative networks. It was claimed that these effects were "larger than the effects documented among other network-related granting programmes" (Malatest and Circum Network Inc., 2007).

An evaluation of the NCE follow-up, the NCE - New Initiatives pilot, found that both renewed and non-renewed networks had "created links between institutions and network partners from diverse institutions, sectors and disciplines, successfully facilitating and expanding the level of research collaboration between researchers and partners through opportunities that would not likely have arisen without the networks". The overall finding was that the NCE-NI pilot had been "very successful in reaching new receptor communities across Canada and achieving effective knowledge mobilization/transfer with hundreds of individuals and organizations from different institutions, sectors and areas of practice" (Bertrand, et.al., 2009). The NCE-NI programme was found to provide added-value in that, through the provision of funding for events and travel, it ensured a "high level of attendance at network meetings and workshops, allowing members to meet and interact with potential partners, and to build and strengthen relationships that previously did not exist". Further benefits arose from the new partnerships that resulted from these network activities, which in turn led to collaborative projects "reportedly worth several million dollars worth of research grants". Other benefits included "reduced duplication of research efforts, increased access to evidence-based practice data and hard-to-reach receptors communities, and raised awareness about the benefits of crossdiscipline or cross-sector networking".

The interim evaluation of the Austrian NANO Initiative found that it had been successful in creating a well networked and visible community out of a fragmented research landscape, mainly based on the eight funded research networks. Each network focuses on a key technology area and works at "a high scientific level" (Technopolis and NMTC, 2006). Its key achievements were.

- Strengthening and networking of Austrian actors

- Developing critical mass and thus national competitiveness

- Acceleration of knowledge transfer and thus better economic take up of nanotechnology

- Anchoring of nanotechnology in the public awareness and science communication and, hence, also for scientific training and, most importantly,

- Bringing together actors that had not worked together before and creating heterogeneous networks.

On the negative side, the networks did not succeed in mobilising the relevant industry sector as was anticipated: this was felt to be the largest challenge facing the initiative. 
Using social network analysis and survey approaches, the evaluation of the Austrian Genome Research programme (GEN-AU) uncovered high levels of networking activities. This programme was designed to support genomics research (including knowledge and technology transfer and training of future scientists) and prepare Austrian researchers for international competition and greater cooperation within the European Union. The evaluation evidence revealed a multidimensional structure of relationships based on a complex system of communication as well as an intensive exchange of research related information, material and personnel among GEN-AU projects. Cooperative activities and the projects were at the centre of the networks. Participants were found to maintain close linkages both within their project-clusters and with players outside their respective clusters. However, the analysis was unable to detect whether important linkages existed before the implementation of the programme. Thus it was not possible to detect a causal correlation between networking activities and research success (Joanneum Research, 2005).

Similar evaluation approaches were used in a 2011 evaluation of the Flemish Innovation Network. Social Network Analysis showed that the network was highly connected, but did not reveal any clusters within the network. A survey of participants found that the network was not a completely intertwined and homogenous structure in which all the advisors knew each other and worked closely together. This suggested a need for the development of hubs - central players with many relationships (Kaashoek, et al. 2011).

Also at a general level, Eickelpasch, et al. (2002) found in the German INNO-REGIO programme that the success of the network in meeting its objectives was significantly impacted by network size. However, there was a trade off to be made between larger numbers of participants, which increased the network's total sphere of competencies and which were able to more successfully implement projects (small networks were apparently better at defining priorities and managing cooperative relationships), and the additional burden of organisation and communication.

The issue of critical mass as a factor for network success was identified by Martin et al. (2004). In the case of the Irish Photonics Association, the relevant companies are relatively small and diverse. They also share little commonality since most do not operate in the same sector. Thus the Association's capability to effectively develop as a network was felt to have been hindered by these factors since the development of equivalent associations in Wales and Canada succeeded as a result of the larger pools of industry players.

Success can also be dependent on the degree of existing experience with network partners. In the Danish Networks Programme, Gelsing and Nielsen (1997) found that, of the 17 factors important for the participation of a firm in a network, "knowledge of one or more of the other participants" was ranked the third most important (behind "access to new markets" and "well defined targets for the network"). As noted by Martin, et al. (2004) "this raises the question of additionality ('deadweight'): is the Network Programme merely achieving formal networks by grant-aiding businesses which have been 'networking' with each other for several years?"

\subsubsection{Internationalisation}

Only one of the studies or evaluation reports reviewed dealt specifically with the issue of internationalisation - that is, the evaluation of the COMPERA Competence Research Centres ERA-NET. This EU level scheme was set up to increase the co-operation and coordination of research activities carried out at national or regional level, However, even in this case, 
internationalisation was only an emerging feature of the Competence Research Centres (CRC) programme. The case studies conducted showed that there is no single 'good practice model' for international collaboration as too much is dependent on the particular context of the CRC, the sector it works with and the scientific and technological focus areas. Nevertheless, in common with evidence from other network programmes, it was shown that international collaboration needs experience and time for trust building, so should be seen as an activity that needs to be developed over time ( $\underline{\mathrm{RCN} / \mathrm{IWT}, 2010)}$.

The study uncovered a number of barriers at the programme level that were found to hamper the internationalisation of the CRCs:

- An absence of policy incentives to co-operate internationally

- (Lack of) funding

- Fear of losing competitiveness advantage if foreign competitors are involved

- Different national framework conditions

- Practical reasons, such as the lack of proximity to suitable partners.

In addition a survey at the Centre level pointed to three clear leading barriers: 1 ) budget and time constraints, 2) difficulties in finding the right partners and 3) IPR regulations.

The evaluation was conducted at a stage that made it too early to assess the effects of international co-operation, since this was only a recent development in the life cycle of the centres. However, no systematic benchmarking, monitoring or evaluation had been carried out in order to be able to assess the progress or effects of internationalisation.

\subsubsection{Participant characteristics}

A further factor influencing the success of network support measures relates to the performance and capabilities of the network partners. In the above mentioned INNO-REGIO study, an analysis of indicators for the performance of enterprises in the (Eastern) German states showed that those already demonstrating above average business performance were more likely to be engaged in the networks and were also able to implement projects more quickly. However, this could be due to the higher propensity of innovative companies to join the networks. A high degree of homogeneity among the participating enterprises was also found to be advantageous to the performance of participating firms. It was felt that a more heterogeneous structure, with a mix of high and medium performing firms, could potentially cause problems for the cohesiveness of the network (Eickelpasch, et al., 2002).

The INNO-REGIO evaluation also found that important network effects result from contacts with partners outside of the networks. Such cooperation can help transfer new knowledge into the network. Thus the flexibility of the network - that is, its ability to respond rapidly to change can be affected by few external relationships but on the other hand an excess of external relationships can endanger the network's cohesiveness. Quite clearly, external contacts have a significant influence on network development. In the case INNO-REGIO the relationships tend to be relatively localised: "70\% of the most important partners of INNO-REGIO participants are located within the same region. There were few divergences from this rule" (Eickelpasch, et al., 2002). 
Further support for the need to involve firms that are inherently good at networking is provided by Pittaway et al. (2004) who note that if networking is crucial for successful innovation firms need to become good at it and that not all firms are able to create and manage their collaborations to maximum advantage. They cite Cohen and Levinthal (1990) who found that both experience and the ability to absorb new technologies and ideas are critical skills in the exploitation of a firm's relationships. Company size is also important: Pittaway, et al. (2004) cite evidence from Hobday's (1994) study which showed that failure in Silicon Valley is linked to networks of small firms being unable to capitalise on the profits that can be made during the maturity stage of innovations. The lesson thus seems to be that firms that are good at networking already will benefit more from network - and that the networks will benefit in turn.

\subsubsection{Sustainable Partnerships}

As networks bring diverse interests together network participation can effective result in more substantive partnerships developing. The 2007 NCE evaluation in Canada found that, under favourable circumstances, "NCE networks were able to create solid partnerships where they did not exist and even where they were unlikely to succeed". (Malatest and Circum Network Inc., 2007).

Partnership formation was identified as an important element of success in the 2009 evaluation of the Canadian NCE - CECR Programme. These centres were created to advance research and facilitate commercialisation of technologies, products and services within a number of priority areas. They had established a range of partnerships with other research centres, industry, the financial community, other CECRs and academia. Partner support and investments were expected to be the key determinants of the long-term sustainability of the CECRs (EKOS Research Associates, 2009). In an evaluation of another NCE follow-up programme (the NCENew Initiative pilot) designed to support networking among well established research teams to develop new partnership, Bertrand, et al., (2009) found that both renewed and non-renewed networks were successful in developing a large number of partnerships (more than 300 in the first 2 years) reaching a wide variety of partner communities in diverse sectors, which recognised the benefits of these interactions. Both cash and in-kind contributions were effectively leveraged by the networks from external partners, providing (according to the evaluators) "significant evidence of receptor engagement in the networks".

The Innovation Network Denmark, a national programme designed to strengthen public-private collaboration and knowledge transfer between public universities and private companies on research and innovation was found to have been effective in attracting a very high level of participation. There are 22 innovation networks spanning a wide range of sectors from robotics and biotech to transport and clothing. Over 3000 enterprises participated in network bridgebuilding activities in 2010 and 2 out of 3 participants came from enterprises with fewer than 50 employees. In 2010, 906 businesses participated in partnership projects which were initiated as a result of network activities: 615 of these enterprises or $67 \%$ had fewer than 50 employees (Christensen, T.A., 2011). However, although evidence of success in terms of attracting participants was found, the factors underlying this were not elucidated.

Fostering the strength of partnerships is a critical element to the success of networking. Pittaway et al, (2004) noted that the UK evidence showed that networks can exist but "may not work effectively because of weak relationships between partners or because firms are unable to extract value from their networks". They cite a qualitative study of eight space research 
innovation projects by Gales and Boynton (1992) which showed an association between weak network ties and increasing uncertainty in the network's role or conditions, with the smallest networks being associated with the projects with the greatest uncertainty. In a longitudinal study of the chemicals industry, Ahuja (2000) demonstrated that the absence of key or important partners within networks ('structural holes') had a negative effect on innovation. He concluded that if particular aspects of the "networking infrastructure are weak (e.g. ScienceIndustry links or supplier interactions) it can have a significant effect on the total networking infrastructure and therefore innovation".

Equally important to the formation of partnerships is their sustainability, particularly after either the objectives of the programme have been met or after the programme funding has come to an end (due to the planned limited lifetime of the programme). As noted in the evaluation of the NCE-New Initiatives Programme, although all the ongoing networks planned to remain active after the end of NCE funding, the sustainability of developed partnerships was dependent on the networks' capacity to secure funding for their infrastructure and operations. At the time of the evaluation, networks had only begun to develop sustainability plans to maintain the progress achieved and to respond to the needs of their stakeholders. Although most ongoing networks had managed to secure financial contributions from partners, "receptor communities", and other network stakeholders to support specific networking, knowledge transfer initiatives, and research activities, they had encountered less success in obtaining a sustainable level of operational funding from external contributors. It was also found that two networks that had been unable to obtain follow-up funding for their operational infrastructure, were not renewed, had dismantled their network infrastructure and moved from a networkcentred to a project-centred approach (Bertrand, et al., 2009).

A lack of flexibility in funding was identified as a potential problem in the Austrian 'export cluster' programme, which had fixed ceilings for the funding and duration for each cluster, irrespective of their specific composition, which varied greatly between networks. "A more flexible approach to duration and funding might have been beneficial for some of the WKÖ clusters, especially those dealing with complex products and/or involving a large number of participants" and "for some of the WKÖ networks, the possibility of a longer funding period or follow-up funding would have a positive effect on their sustainability (Polt, in OECD, 2001).

Another issue concerning sustainability is the threat posed by the loss of network members over time, particularly if these are key participants. This can also be a concern during the network's formative stages: if progress with the development of partnerships or the delivery of support funding is too slow then key partners may be lost before significant network effects have a chance to develop (Eickelpasch, et al., 2002).

\subsubsection{Leading edge research}

Few of the networks strive to support leading edge research and for those that do, there is surprisingly little evidence of research impacts.

The 2002 evaluation of the Canadian NCE Programme found that specific impacts could often be linked to the different processes used within networks. Many of the network achievements were felt to be of high economic and social importance, and many examples of potential applications were provided. About one-third of researchers, and nearly $60 \%$ of industrial partners, considered their networks had delivered groundbreaking scientific and/or 
commercial results and a high proportion of industrial partners (85\%) were satisfied or very satisfied with their NCE experience overall. (Rank, 2002).

In contrast, the 2007 evaluation of the NCE Programme did not attempt to examine new evidence on the excellence achieved by the networks in research (since the complex task was beyond the study's resources and it was felt that the application process would, in any case, ensure the selection of participants with proven track records in research). However, interviews with experts revealed that they considered the research performed by the NCE networks under review to be of a high standard. The evaluation also found, through a light touch bibliometric analysis, that the proportion of NCE researchers included in the Thompson Scientific Citation Database highly cited researchers list was four times higher than the proportion of all Canadian researchers on the list (i.e., 1.5\% versus 0.4\%) (Malatest and Circum Network Inc., 2007).

The evaluation of the Belgian IAP Programme utilised a peer panel approach to assess research quality: nearly half of the networks funded were considered world-class, with some worldleading research being carried out. Other networks were assessed to be performing worthwhile research at the national level, contributing significantly to the Belgian research environment and training. The panels saw mounting evidence of the IAP programme contributing to consolidating the scientific communities within Belgium and integrating them within Europe (IDEA and ADE, 2011).

\subsubsection{Impact on innovation}

Networks promote innovation within and across firms they also assist in the diffusion of innovations. However, as stated above, only very few of the networks under study undertook quantitative evaluations of the relationship between networks and innovation. A recent study (DAMVAD, 2011; Alslev Christensen, 2011) of the Innovation Network Denmark programme mentioned above examined what it termed the 'behavioural impacts'. These were defined as whether participation in network increases probability of being innovative, of entering into R\&D partnerships and whether network membership encourages greater use of existing innovation programmes.

Comparing the innovation performance of a sample of 1,225 firms belonging to innovation networks with an equivalent number of matched non-network firms the study found that $8.3 \%$ firms had an innovation outcome - new products or new process, compared $1.7 \%$ of nonnetwork firms. The estimation result showed that participation in innovation networks and increases the probability to innovate by $48 \%$ compared to non-network firms in the first year of participation and this increases to $466 \%$ relative to the control group in the fourth year. Network participation increases the probability of R\&D collaborations by a factor of 4 after two years in the network relative to the control group while it also led to an increased use of national and international programmes. Network firms were over 1.4 times more likely to participate in other programmes after two years and 2.2 times more likely after five years (DAMVAD, 2011).

Although the time series data used for the analysis was not sufficiently extensive to allow for an investigation into the economic impacts, the evaluation report cited a Danish study covering 2,694 firms between 1997 and 2005 that showed additional investment in innovation activities yields a return on investment of $20 \%$ based on the impact that labour has on productivity. 


\subsubsection{Research Training}

With the exception of the Canadian NCE programmes, the issue of research training has not been an important focus of the majority of the supported networks considered. The Canadian NCE networks are large-scale, academically-led virtual research networks that bring together partners from academia, industry, government and not-for-profit organizations. Training is an important component of the programmes which funds research partnerships between academia, industry, government, and not-for-profit organisations.

In its evaluation, the programme was found to offer participating students opportunities with regard to publications and conferences, ethical debates and exposure to real-life practices. It also helped to develop greater complementarity between the students' study areas and their subsequent field of employment. The disciplinary field involved also impacted the research training experience, with health sciences allowing easier access to multi-disciplinary initiatives than in natural sciences and engineering or in social sciences and humanities while health sciences and social sciences and humanities gave easier access to ethical debates than did natural sciences and engineering. However, the training objective of the NCE Programme appeared to have been achieved only in part (Malatest and Circum Network Inc., 2007).

The follow on programme, the NCE-New Initiatives Programme was found to have succeeded in "Pan-Canadian capacity building", particularly for students. "Hundreds of graduate students were actively engaged in network activities (including participation in governance or operational committees; in student-run auxiliary networks; learning and skills development programmes; knowledge mobilisation projects; poster and oral presentation sessions). The networks provided students with travel subsidies to national and international meetings and allowed them to benefit from valuable networking opportunities with established researchers and field practitioners (Bertrand, et al., 2009).

\subsubsection{Transfer and exploitation of knowledge and technology}

Networks not only facilitate the transfer and exploitation of knowledge and technology, they engender the build up of trust between and among network partners ${ }^{6}$. However these issues have not been well represented in the case studies considered.

In the case of the Canadian NCE networks the 2002 Evaluation found positive indication that the networks were conducive to knowledge transfer to industry: at least $88 \%$ of the highly qualified personnel trained by the networks in 2000-2001 found employment after leaving the network (typically after graduation) and about half of these were subsequently employed by industry,. Significant numbers also gained employment with the government. Further, other forms of knowledge transfer successes noted in the evaluation included the creation of 97 spin-off companies, and 56 patents from 170 applications filed in 2000-2001.

The evaluation noted that this represented only a portion of NCE technology transfer since several of the networks relied on other mechanisms to achieve their impacts (Canadian NCE Evaluation, 2002). The later (2007) evaluation found that the programme performed better than other comparable network and collaboration-related programmes in terms of the

$6 \quad$ The issue of trust within networks is explored in a NESTA Guest article by Karen Stephenson, 2010 (see:http://www.nesta.org.uk/publications/guest articles/assets/features/how networks of trust can unlock innovation) 
generation of "patents and licenses, the formation of new companies and the improvement of the health of existing ones, and the creation of new products, services and processes". In addition, the utilisation of research findings was significantly higher among NCE public sector partners in 2007 than in the average government agency in 1998, suggesting that the Programme had performed well in this respect (Malatest and Circum Network Inc., 2007).

The 2002 NCE evaluation (Rank, 2002) noted that one area of potential weakness concerned the protection of Intellectual Property. These were caused mainly by the variety of IP ownership rules in operation at the various participating universities, and variable levels of trust and collaboration between individual networks and their university Industry Liaison Offices. A lesson here is that strong IP arrangements are required in order to support mutual trust between the network participants when it comes to the issue of commercialisation of research results. Interestingly, and in slight contradiction to this assessment, a significant finding of the evaluation was that the (industrial) partner organisations were "typically as satisfied, or even more satisfied, with NCE design, delivery, and impacts than were the network officials and researchers." This is an unusual finding in evaluations, as typically programme officials are the most positive about any given programme, researchers are slightly less satisfied, and partners (especially in industry) are the least satisfied (even if still generally positive) (Rank, 2002).

The issue of mutual trust was also found to be a significant factor in the German INNO-REGIO Programme which sought to develop regional competencies through linking key regional actors, including firms, universities and research centres. While contractual safeguards were found to offer "basic guidelines for cooperation, they only offer limited protection against abuses; trust is thus an indispensable basis for all cooperation". According to the study, overall the level of trust between network participants was found to be quite high. (Eickelpasch, et al., 2002).

Further support is provided by a review of UK networking experience by Pittaway et al. (2004) which notes that network ties tend to be much more conducive for the exchange of information and knowledge between partners than market mechanisms. "Socialisation through networks engenders trust, which makes network ties a superior conduit for information flow. Due to its positive impact on information flows, trust based behaviour characterised by implicit openended contracts is cited as a crucial factor in enhancing innovation through inter-firm collaboration (Hausler et al, 1994, Hoang and Antoncic, 2003) and an integral reason for interfirm networks' longevity (Lorenzoni and Lipparini, 1999)". Polt (in OECD, 2001) makes the same point regarding the Austrian Kplus programme - "as the establishment of long-term relations is the main goal of the programme, stability and trust are the primary targets". The issue of trust assumes greater significance in the Austrian 'export clusters' programme: "In this type of network, stability and trust are constantly challenged by the diverging (short-term) interests of the participant firms. This is particularly evident in the "clusters" with the greatest numbers of members, a high share of SMEs and a large number of competitors trying to cooperate. In some cases, it took a long time to establish trust, in others this process was yet to be been completed. Some of the "clusters" may even disintegrate. Thus, the task for the cluster manager is extremely delicate. As recent experience with the conduct and performance of the various clusters has shown, the cluster manager plays a key role as a "go-between". The success of the cluster hinges mainly on his/her performance in this role" (Polt, in OECD 2001).

Finally, echoing this particular point, Martin et al. (2004) in their review of Irish network initiatives, state that the issue of trust is of particular importance in networks "whose membership includes companies that compete against each other". 


\subsubsection{Cost effectiveness}

Although there are limitations in assessing the cost-effectiveness of this type of innovation support, several evaluations - typically those conducted on North American programmes - do examine this issue. In the case of the Canadian NCE Programme, the 2007 evaluation measured cost effectiveness by comparing the NCE model against alternative delivery including network programmes operated within the three granting councils, a national network programme under an independent Secretariat and the NCE-NI model where funding supports only networking efforts, not research. The overall result was found to be positive: the programme compared favourably to other programmes with regard to its operating costs and ranked second with regard to the ratio of costs per $\$ 1,000$ of research funding and the cost per grant, whilst it ranked first with regards to leveraging research money and other contributions from sources external to the programme (Malatest and Circum Network Inc., 2007).

The NCE-New Initiatives Programme also provided a high level of value for money, particularly in terms of the value of the grants versus the quantity and quality of outputs. In addition, the external contributions leveraged by ongoing NCE-NI networks, calculated as a proportion of their total NCE-NI funding, was nearly twice as much as that of the Networks of Centres of Excellence over the same period (Bertrand, et al., 2009). "The comparison of external fund leveraging between NCE-NIs and full NCEs provides additional evidence that the NCE-NI pilot was delivered cost-effectively, from the perspective of both the funded initiatives and the pilot. In fact, the NCE-NIs were more successful in leveraging external contributions (in-cash and in kind contributions, not including research funds received by individual network members) compared to the full NCE Networks. Over their first two years (2006-07 and 2007-08), the external contributions leveraged by ongoing NCE-NI networks, calculated as a proportion of their total NCE-NI funding, was nearly twice as much as that of the NCEs:

- NCE leveraging/NCE budget (average of 2006-07 and 2007-08): 71.5\%

- NCE-NI leveraging/NCE-NI budget (average of 2006-07 and 2007-08): 134\% (160\% for the second year alone).

The authors concluded that, "as a proxy indicator of networking and knowledge transfer, this finding suggests excellent performance by the NCE-NI pilot in this regard. This finding is all the more significant because, unlike the full NCEs, the external contributions leveraged by the NCENI do not generally include research funds obtained by partners".

Further evidence on cost effectiveness is provided by the review of Japanese Industrial Cluster Policy programme conducted by Nishimura and Okomuro (2011). They studied the ICP cluster programme which started in 2001. Under this programme the Ministry for the Economy, Trade and Industry supports network formation activities among the participants of existing clusters and offers information on and contacts with the business and academic community as well as funding opportunities. The Nishmura and Okomuro analysis showed that indirect support measures were more effective and network formation than other kinds of support such as R\&D. Moreover indirect softer policies such as network support seemed to have a stronger effect on firm performance than R\&D. Thus, given that policies such as direct R\&D support cost much more than indirect support programmes they conclude that their results are suggestive of the effectiveness of such indirect support systems that remove obstacles and relax constraints in the networks. 


\subsubsection{Longer-term outcomes}

As noted earlier, the variety of activities encompassed by networking programmes tends to militate against the definition and measurement of clear longer term outcomes. Indeed, in their

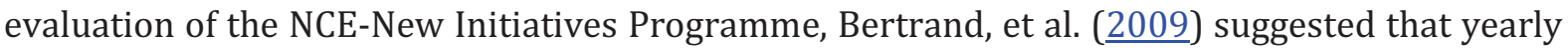
reporting requirements and the selection of indicators should be modified and that the midterm review occurred too early to provide a meaningful assessment of whether the programme objectives were being obtained.

However, some evaluations have made an assessment of achievements over the longer term. For example, the 2002 Evaluation of the Canadian NCE (Rank, 2002) found that the programme appeared to have "been successful or very successful in meeting its overall goal and four [out of five] of its specific objectives". The programme was found to be less successful in terms of developing and retaining world-class researchers essential to Canada's productivity and economic growth".

\subsubsection{Other issues/factors}

There is some evidence that association with high quality research network initiatives can act as an esteem indicator for the actors involved. For example, according to the evaluation of the Canadian NCE-New Initiatives Programme, the "NCE" branding was found to increase the buy-in of "top researchers, organisations, and the Board of Directors' members in the networks" (Bertrand, et al., 2009). A similar finding is provided by Martin et al. (2004) where they state that the development of a clear identity for a network can be critical for its longevity: "The M50 network is an example of brand identity which has assisted the network to expand its membership to include University College Dublin. A clear and defined identity for the network assists in highlighting to members of its own objectives and activities. The Atlantic University Alliance is another example of a network which gained a high brand-name recognition".

\section{Lessons}

\subsection{Lessons concerning networks}

The range of network types covered in this review makes it difficult to draw specific lessons according to such variables as the objectives of the programme, the form of support provided, the intended network participants and actors, and the nature of the networking activities supported. Likewise, it is difficult to map out a set of variables and to indicate what works and what does not work in regard to policy instruments. These factors, together with the need to be sensitive to the context within which policy interventions operate, mean that there is no 'onesize-fits-all' recipe for the design and implementation of network support instruments.

Therefore, a number of general lessons are provided and a distinction is only made, according to specific network characteristics where such evidence is available, or where particular policy models have been successful.

One general finding appears to be that in the evaluations, the evidence of success (and likewise, the rationales and objectives of many network support programmes) tends to focus on the creation and the behaviour of a network per se (with an implicit assumption that it will generate a range of positive effects and impacts on innovation), rather than looking directly for the evidence that such impacts have been achieved. In a sense, this is equivalent to the creation 
of a logical framework for the design of a measure in which the objectives and effects/impacts are defined, but where the outcomes of specific activities are not. Consequently, the evaluations also tend to omit this element of the evidence.

\subsubsection{General lessons}

1. There is a very broad range of network configurations, which differ depending on the form of innovation, industry and the purpose of the network.

2. Networks fail for a variety of reasons: but lack of demand, trust, commitment and excessive bureaucracy seem to major causes. [Section 4.1.12]

3. Despite (or because of) the diversity and the complexity of various network forms, there is little evidence to explain which forms of network most contribute to innovation or indeed whether networks do lead to innovation.

4. Networks can have very positive effects on the stimulation of learning processes and the enhancement of skills levels. [Section 4.1.11]

5. All participants should actively manage their networking relationships; experience and network management competencies can strongly influence the gains to be made from network participation. [Section 4.1.3]

6. Strong network management and leadership (such as through a board of directors), coupled with transparent and efficient administrative processes are overwhelmingly cited as essential contributory factors for network success. [Section 4.1.3]

\subsubsection{Lessons for policy}

7. Established (informal) networks, or pre-existing connections and relationships form the optimal basis for the establishment of more formal policy-led initiatives for the creation or development of networks. [Section 4.1.1]

8. In the formulation of policies for network creation, the consideration of local conditions and requirements is essential. [Section 4.1.1]

9. The absence of demand appears as a strong cause for network failure: it is essential the there is a strong demand for the network, the benefits it offers and its anticipated outputs. [Section 4.1.1]

10. Similarly, to the above point, it is essential that network outputs are closely tailored to the needs of the user/recipient community, both inside and outside of the network itself. [Section 4.1.1]

11. It is essential to obtain the commitment and support of all partners in the network weak links or weak support will hinder network success. All partner organisations should have a strong and clear role in the network planning and research processes (and not just participate in "name only"). [Section 4.1.4]

12. Government intervention can act as both a positive and negative force affecting the sustainability of particular networks and network infrastructures. It can be very difficult to predict the development path of a network since it can be influenced by unpredictable events or by the unintended effects of other policy action or the regulatory context. In the absence of a bottom-up process of self determination, top-down initiatives that select target industries, technologies or scientific fields, may not succeed. [Section 4.1.2] 
13. Following from the above point, there is however a trade-off between too much public intervention (with the risk of creating artificial networks with little participant ownership) or too little public intervention (with a loss of opportunities caused by a failure to remove barriers that allow network activities to proposer). Thus, there is a need to strike a balance between the two approaches. [Section 4.1.2]

14. Policy instruments that facilitate network formation and development (such as support for network brokers or other intermediary organisations) are often successful. While all firms in a network benefit from it, the establishment and management costs are borne largely by the network organiser. Public intervention can therefore be used to mitigate this 'free-rider' effect. [Sections 4.1.2 and 4.1.3]

15. Network success is often predicated on the forging and strengthening of mutually beneficial relationships, many of which typically take years to develop. Policymakers need to be sensitive to this and allow sufficient timeframes for the demonstration of results. [Sections 4.1.4, 4.1.5 and 4.1.12]

16. Network sustainability is particularly sensitive to the timing of funding flows - adequate time must be given to allow the network to become self-sustaining and the role of transitional funding can help to promote sustainable effects and achievements, particularly since their success may continue to generate demands from external parties after the end of the programme lifetime. [Section 4.1.8]

17. A commonly cited prerequisite for self-sustainability is if the network is able to act independently from government and funding organisations and to formulate its own decisions concerning strategic orientation and daily operations. Excessive, government enforced bureaucratic processes are a major contributor to network failure. [Section 4.1.8]

\subsubsection{Firm-to-firm effects}

18. The effectiveness of networking between firms is principally driven by personal and informal relations. [Section 4.1.2 and elsewhere]

19. Where firms have a diversity of relationships with external organisations, there is a positive impact on innovation and performance. Thus it is important that, where firms' innovation performance is a key policy goal, all elements of the value chain are included (i.e. a large number of companies, inclusion of financing institutions, supplier chains, relevant public-private-partnerships). [Section 4.1.2]

20. However, the burden of coping with the diversity of participants' needs can pose a strain on network administrations and management. [Section 4.1.5]

21. While essential in all forms of network, the issue of trust is of paramount importance in affecting the success of firm to firm networks. Good, clear IP arrangements are essential in helping to engender trust but are not, on their own, a substitute for trust. Weak or complex IP arrangements are frequently cited as a cause of lack of network success. [Section 4.1.12]

22. Firm productivity and the likeliness that innovation will succeed are increased if suppliers, co-suppliers and distributors are integrated in innovation projects. [Section 4.1.2] 


\subsubsection{Lessons from heterogeneous networks}

23. Non-industrial actors, such as science partners, third parties and institutional mechanisms (e.g. incubators) can act as neutral network brokers between firms and thus play an important role. [Section 4.1.2]

24. As in firm to firm networks, relationships are enhanced by the development of mutual trust and IPR arrangements are also a vital component towards the establishment of trust. [Section 4.1.12]

25. The presence of world-class scientific leadership and expertise is strongly correlated with the success of science-oriented networks. However, efforts should be made to ensure that true collaboration among the best researchers in the field is fostered rather than "collaborations of convenience" or where the network is no more than an "old boy's club". [Section 4.1.5]

26. Where possible, and particularly in the case of scientific networks, in order to maximise the network potential they should be built around an integrated research programme with mutually self-supporting themes to which the network researchers are fully committed - rather than around a series of unlinked projects. [Section 4.1.5]

27. Similarly, where a multidisciplinary approach is adopted, the "peripheral disciplines" should be well integrated into the overall network strategy, rather than being present for the sake of appearance or inclusivity. [Section 4.1.5]

28. Industry-higher education networks can be fostered through the provision of a range of complementary instruments for the support of industry-academic relationships. These include: intermediaries such as technology transfer organisations, science and technology parks; University-based industry liaison offices within third level colleges; enhancement of the regulatory environment to remove obstacles to industry academia collaboration; funding co-operative research projects that allow for the creation of specific (physical or virtual platforms) that facilitate actors from both industry and academia to work together in a specified technology area (e.g. competence centres programmes).

\subsubsection{Other lessons}

29. Network success is often associated with a positive external and internal perception of participants and their communication strategies (for example as measured by the number of positive press-reports). In this regard, branding of the network can play an important role. [Section 4.1.14]

30. Dissemination of results and the effort expended on this have been identified as contributory factors to success, particularly in field specific networks. [e.g. Canadian NCE Programme]

\subsection{Lessons for evaluation and the need for future research ${ }^{7}$}

31. The complexity of networks and the diversity of motivations, rationales, activities, outputs, outcomes and effects make the task of evaluation very difficult. Evaluations tend, therefore, to focus on specific aspects of network behaviour rather than covering the complete set of potential variables. Thus in many of the studies discussed here, the

${ }^{7}$ It should be noted that the findings of the literature review tend to confirm many of the challenges presented in Section 2.2.2. 
evaluation of networking activities was understood as an input for project management and programme development.

32. Timing of evaluations is, as in many cases, a critical issue. Several of the evaluations and reviews found it difficult to make quantitative assessments of network effects, largely because many of the outcomes that could be used as proxies for this measure, such as patenting behaviour had yet to materialise. Moreover in many cases there was no baseline of existing capabilities and networking from which progress could be measured. Consequently the evaluation of network quality followed from activity analyses and interview responses.

33. Network success can be and is often measured through the quality, frequency and number of linkages/interactions. These indicators may be measured through a range of approaches, from interviews with partners and customers of networks to structural investigations.

34. Assessment of network activities is often enhanced if appropriate monitoring and data collation processes are in place through the lifetime of the programme, provided these are designed in such a way as not to pose bureaucratic burdens and barriers to participation.

35. Network sustainability and the achievement of the desired/anticipated structural changes should form the key considerations of evaluators.

36. To better understand the ways in which networks function, a much more systematic, meta-evaluation approach would be needed. Such an approach should identify a variety of network programmes and apply similar analytical tools, so that the context conditions, programme aims, programme mechanisms and effects can be put into a systematic relation. This is a large research programme, for which - as this overview has shown - not enough empirical data is available and primary data would have to be collected.

37. A systematic network research agenda would also have to be much more rigorous in identifying the meaning of networking, network structures and nature of network linkages for the final purpose, i.e. innovation performance and capabilities and the relation between sustainability of networks and the necessary renewal and "attrition rate" of network members. 


\section{References}

Ahuja, G., 2000. Collaboration Networks, Structural Holes, and Innovation: A Longitudinal Study. Administrative Science Quarterly, 45 (3): 425-455.

Alslev Christensen, T., 2011. Business Research, Development and Innovation in Denmark policies and effects. Danish Ministry of Science, Innovation and Higher Education (DASTI).

Bertrand, F., Picard-Aitken, M., Lecomte, N., Mercure, S., NicNiocaill, B., Caruso, I., 2009. Summative Evaluation of the Networks of Centres of Excellence - New Initiatives, Final Evaluation Report. Science Metrix.

Bruno, N, Giarracca, F, Horvath, A, Kamburow, T, Navarrete Moreno, C, Parker-Rhodes, L. and Simmonds, $P$. 2011. http://ec.europa.eu/regional policy/sources/docgener/evaluation/pdf/eval2007/innovation a ctivities/inception report.pdf. Technopolis-Report to DG Regional Policy.

Cohen, B. W., Levinthal, D., 1990. Absorptive Capacity: A New Perspective on Learning and Innovation. Administrative Science Quarterly, 35 (1): 128-152.

DAMVAD, 2011. The impacts of cluster policy in Denmark - An impact study on behaviour and economical effects of Innovation Network Denmark. Danish Agency for Science, Technology and Innovation.

Eickelpasch, A., Kauffeld, M., Pfeiffer, I. , 2002. The InnoRegio - Program: A new way to promote regional innovation networks - empirical results of the complementary research. 42nd conference of the European Regional Science Association: "From Industry to Advanced Services: Perspectives of European Metropolitan Region”, Dortmund, Aug 27 2002 12:00AM.

EKOS Research Associates Inc., 2009. Formative Evaluation of the Networks of Centres of Excellence - Centres of Excellence for Commercialization and Research Program: Final Report. EKOS Research Associates Inc.

European Commission, 2003. Raising EU R\&D Intensity: Improving the Effectiveness of Public Support Mechanisms for Private Sector Research and Development - DIRECT MEASURES. European Commission EUR 20716: Brussels.

European Commission, 2006. Community Framework for State Aid for Research and Development and Innovation. Official Journal of the European Union.

Freeman, C., 1982. Technological Infrastructure and International Competitiveness. Globelics Conference 'Innovation Systems and Development Strategies for the Third Millennium', Rio de \aneiro, Nov 22003.

Freeman, C., 1991. Networks of Innovators: A Synthesis of Research Issues. Research Policy, 20 (5): 499-514.

Gales, L. M., Boynton, A. C. , 1992. Information ties and innovation management: A qualitative assessment of information processing and the strength of weak ties. The Journal of High Technology Management Research, 3 (2): 169-188. 
Gelsing, L. and Nielsen, K. , 1997. Promoting Inter-firm Networks in Industrial Policy - Danish Evidence. DRUID, Snekkersten, May 61997 12:00AM.

Hausler, I., Hohn, H-W., Lutz, S. , 1994. Contingencies of innovative networks: A case study of successful interfirm R \& D collaboration. Research Policy, 23 (1): 47-66.

Hjelt, M., Ahonen, P-P., Pessala, P. , 2009. Impact Evaluation of the Finnish Programmes for Centres of Excellence in Research 2000-2005 and 2002-2007. Academy of Finland.

Hoang, H., Antoncic, B. , 2003. Network-based research in entrepreneurship: A critical review. Journal of Business Venturing, 18 (2): 165-187.

Hobday, M., 1994. The limits of silicon valley: a critique of network theory. Technology Analysis \& Strategic Management, 6 (2): 231-245.

IDEA Consult and ADE, 2011. Ex-post evaluation of the IAP programme (phase VI, 2007-2011). Belgian science policy office (Belspo) : Brussels.

IRE subgroup, 2008. Regional clustering and networking as innovation drivers. IRE subgroup.

Joanneum Research, TIA Consulting and Austrian Institute for SME Research, 2005. Austrian Genome Research Programme GEN-AU: Mid Term Programme Management Evaluation. Federal Ministry for Education, Science and Culture: Vienna.

Kaashoek, B., Holland, C., te Velde, R., Veldkamp. I., 2011. The Flemish Innovation Network: Structure, Workings and Future set-up. IWT.

Lemola, T., Lievonen, I., 2008. The role of innovation policy in fostering open innovation activities among companies. Vision ERAnet.

Liston C. , 1996. Worldwide connections: A status report on interfirm collaboration programs. Firm Connections, 4 (1-7).

Lorenzoni, G., Lipparini, A. , 1999. The leveraging of interfirm relationships as a distinctive organizational capability: A longitudinal study. Strategic Management Journal, 20 (4): 317-338.

Lundvall, B.Å. , 1992. National System of Innovation: Towards a Theory of Innovation and Interactive Learning. Printer Publishers: London.

Malatest, Circum Network Inc, 2007. Evaluation of the Networks of Centres of Excellence Program. prepared for the Interagency Evaluation Steering Committee on behalf of the NCE Steering Committee: Ottawa.

Martin and Associates, Vision Consulting, Nauwelaers, C., 2004. Innovation Networks. Forfas.

McDonald, F., Huang, Q., Tsagdis, D., Tüselmann, H., 2007. Is there evidence to support portertype cluster policies? . Regional Studies, 41 (1): 39-49.

Nishimura, J., Okamuro, H. , 2011. Subsidy and networking: The effect of direct and indirect support programmes of cluster policy. Research Policy, 40 (5): 714-727. 
O'Doherty, D., 1998. Networking in Ireland-Policy responses", in Sustaining Competitive Advantage, Proceedings of National Economic and Social Council (NESC) Seminar. NESC Research Series, Dublin.

OEC, 2004. Networks, Partnerships, Clusters and Intellectual Property Rights: Opportunities and Challenges for Innovative SMEs in a Global Economy. 2nd OECD Conference of Ministers Responsible for SMEs, Istanbul, Jun 32004.

OECD, 2011. Business Innovation Policies: Selected Country Comparisons. OECD: Paris.

OECD, 2001. Innovative Networks: Co-operation in National Innovation Systems. OECD: Paris.

Perrin, B., 2002. How to - and How Not to - Evaluate Innovation. Evaluation, 18 (1): 13-28.

Pittaway, L., Robertson, M., Munir, K., Denyer, D. and Neely, A. , 2004. Networking and Innovation in the UK: A Systematic Review of the Literature. Advanced Institute of Management Researc.

Porter, M., 1990. The competitive advantage of nations. Macmillan: London.

Raines, P., 2002. The Challenge of Evaluation Cluster Behaviour in Economic Development Policy. University of Strathclyde, Glasgow: http://www.eklaster.org/old/ files/stale/RAINES.PDF.

Rank, D., 2002. Evaluation of the Networks of Centres of Excellence: Final Report. KPMG Consulting LP.

RCN, IWT, 2010. Report on Monitoring and Evaluation of Competence Research Centres (CRC). COMPERA.

Rychen, F., Zimmermann, J-B. , 2002. Birth of a cluster: The microelectronics industry in the Marseilles metropolitan area. International Journal of Technology Management, 24 (7-8): 792$\underline{817 .}$

Stahl-Rolf, S., Hamann, 0. , 2003. International Experiences with Ex-ante and Ex-post Evaluations of Networks of Innovation. VDI-Technology Centre: Dusseldorf.

Stahl-Rolf, S., Hamann, O., Wilkens, B. M., Hausberg, B., 2002. Networks of Innovation in International PerspectiveNetworks of Innovation in International Perspective. Federal Ministry of Education and Research: Düsseldorf.

Stephenson, K., 2010. How networks of trust can unlock innovation. NESTA Guest Article, : http://www.nesta.org.uk/publications/guest articles/assets/features/how networks of trust can unlock innovation.

Technopolis, NMTC, 2006. Interimsevaluierung der Österreichischen NANO Initiative. Endbericht: Wien.

van der Veen, G., Arnold, E., Boekholt, P., Deuten, I., van Giessel, I-F., de Heide, M., Vullings, W., 2005. Evaluation Leading Technological Institutes: FINAL REPORT. Technopolis. 


\section{Manchester Institute of Innovation Research}

The Manchester Institute of Innovation Research (MIoIR) is the research centre of excellence in the Manchester Business School (MBS) and The University of Manchester in the field of innovation and science studies. With more than 50 full members and a range of associated academics from across the University, MloIR is Europe's largest and one of the World's leading research centres in this field.

The Institute's key strengths lie in the linkage and cross-fertilisation of economics, management and policy around innovation and science. Building on forty years of tradition in innovation and science studies, the Institute's philosophy is to combine academic rigour with concrete practical relevance for policy and management. This includes broad engagement with and research for policy makers and societal and industrial stakeholders in the Manchester City Region, across the UK and internationally. MIoIR is also firmly committed to a range of teaching activities within and beyond MBS and integrates a strong and successful PhD programme into its research activities. The Institute has a visitor programme for academics and management and policy practitioners and provides a range of popular and high level executive education courses on evaluation, foresight and S\&T Policy. 